\title{
TRPM2 ion channels steer neutrophils towards a source of hydrogen peroxide
}

\author{
Hassan Morad ${ }^{1}$, Suaib Luqman ${ }^{1,2}$, Chun-Hsiang Tan ${ }^{1,3}$, Victoria Swann ${ }^{1,4}$ \& Peter A. \\ McNaughton ${ }^{1,5}$ \\ 1. Wolfson Centre for Age-Related Diseases, King's College London, Guy's Campus, \\ London Bridge, London SE1 1UL, UK
}

2. Molecular Bioprospection Department, CSIR-Central Institute of Medicinal and Aromatic Plants, P.O. CIMAP, Lucknow, Uttar Pradesh-226015, India

3. Department of Neurology, Kaohsiung Medical University Hospital, and Graduate Institute of Clinical Medicine, College of Medicine, Kaohsiung Medical University, Kaohsiung, Taiwan

4, School of Cellular and Molecular Medicine, University of Bristol.

5. To whom correspondence should be addressed at peter.mcnaughton@kcl.ac.uk

\section{Short title: TRPM2 ion channels steer neutrophils}

\begin{abstract}
Neutrophils must navigate accurately towards pathogens in order to destroy invaders and thus defend our bodies against infection. Here we show that hydrogen peroxide, a potent neutrophil chemoattractant, guides chemotaxis by activating calcium-permeable TRPM2 ion channels and thus generating an intracellular leading-edge calcium "pulse". The thermal sensitivity of TRPM2 activation means that chemotaxis towards hydrogen peroxide is strongly promoted by small temperature elevations, suggesting that an important function of fever may be to enhance neutrophil chemotaxis by facilitating calcium influx through TRPM2. Chemotaxis towards conventional chemoattractants such as LPS, CXCL2 and C5a does not depend on TRPM2 but is driven in a similar way by leading-edge calcium pulses. Other proposed initiators of neutrophil movement, such as PI3K, Rac and lyn, influence chemotaxis by modulating the amplitude of calcium pulses. We propose that intracellular leading-edge calcium pulses are universal drivers of the motile machinery involved in neutrophil chemotaxis.
\end{abstract}




\section{Introduction}

The first line of defence against pathogen invasion is formed by tissue-resident "sentinel" macrophages that detect characteristic pathogen-associated molecular patterns, engulf the invading pathogens and then kill them, partly by generating a "respiratory burst" of toxic free radicals. Following interaction with pathogens, macrophages release a range of chemoattractant signals, including cytokines and chemokines such as IL1, TNFa and CXCL2. In addition, destruction of bacterial proteins releases chemoattractant signals, such as fMLP and activation of the complement cascade releases signals, such as C5a. In response to the release of these chemoattractants, circulating neutrophils leave the blood space and navigate up the chemoattractant gradients to locate and attack invading pathogens. A subsequent wave of macrophages and lymphocytes, such as natural killer (NK) T cells, joins the attack in a similar way ${ }^{1}$.

While these key features of the early response of the innate immune system have been known for some time, important questions remain. Are other chemoattractants also important? Hydrogen peroxide $\left(\mathrm{H}_{2} \mathrm{O}_{2}\right)$ is a neutrophil chemoattractant in vitro ${ }^{2}$, and more recent in vivo evidence shows that $\mathrm{H}_{2} \mathrm{O}_{2}$, generated by the reaction with water of reactive oxygen species (ROS) produced by the NADPH oxygenase DUOX, forms a concentration gradient extending more than $100 \mu m$ from a site of injury, and moreover that $\mathrm{H}_{2} \mathrm{O}_{2}$ is a critical early guidance signal for neutrophil chemotaxis in vivo ${ }^{3-11}$. How does $\mathrm{H}_{2} \mathrm{O}_{2}$ act as a neutrophil chemoattractant? More generally, what are the cellular signalling mechanisms that guide neutrophils up gradients of chemoattractant molecules? The present study aimed to elucidate the mechanisms that couple gradients of $\mathrm{H}_{2} \mathrm{O}_{2}$ and other chemoattractants to neutrophil chemotaxis.

\section{Results}

\section{Hydrogen peroxide is a potent neutrophil chemoattractant both in vivo and in vitro}

We used a range of methods, both in vivo and in vitro, to confirm that $\mathrm{H}_{2} \mathrm{O}_{2}$ is a neutrophil chemoattractant. $\mathrm{H}_{2} \mathrm{O}_{2}$ injected into the peritoneal space in vivo recruits mouse neutrophils, with efficacy observed down to a concentration of 10nM (Fig. 1A). Recruitment remains significantly elevated at concentrations between $10 \mathrm{nM}$ and $10 \mu \mathrm{M}$ but is inhibited at $100 \mu \mathrm{M}$. The well-established neutrophil chemoattractant fMLP also potently recruits neutrophils, with a similar efficacy to optimal concentrations of $\mathrm{H}_{2} \mathrm{O}_{2}$.

We next used the classical Boyden chamber method to measure neutrophil recruitment by $\mathrm{H}_{2} \mathrm{O}_{2}$ in vitro. In this assay, a membrane with $3 \mu \mathrm{m}$ pores, through which only neutrophils can penetrate, separates the neutrophil and chemoattractant compartments. $\mathrm{H}_{2} \mathrm{O}_{2}$ down to $1 \mathrm{nM}$ concentration caused significant neutrophil recruitment through the membrane, with maximal recruitment between $10 \mathrm{nM}$ and $10 \mu \mathrm{M} \mathrm{H}_{2} \mathrm{O}_{2}$ and a similar inhibition to that observed in vivo at $100 \mu \mathrm{M}$ (Fig. 1B).

Similar results were obtained using a second in vitro method, the ibidi $\mu$-slide, in which neutrophil motion is continuously tracked under a microscope (Fig. 1C, D and Supplementary Video 1). Fig. $1 \mathrm{C}$ shows the speed of movement of neutrophils as a function of concentration of $\mathrm{H}_{2} \mathrm{O}_{2}$. Neutrophils undergo random movements in the absence of $\mathrm{H}_{2} \mathrm{O}_{2}$, so the average speed is not zero in the absence of $\mathrm{H}_{2} \mathrm{O}_{2}$ even though there is no significant directed movement (see Fig. 1D). The average speed is increased in a gradient of $1 \mathrm{nM} \mathrm{H}_{2} \mathrm{O}_{2}$ distributed over $1 \mathrm{~mm}$, the distance between the compartments containing $\mathrm{H}_{2} \mathrm{O}_{2}$ and DMEM. Average speed is maximal between $0.1 \mu \mathrm{M}$ and $10 \mu \mathrm{M} \mathrm{H}_{2} \mathrm{O}_{2}$ and is inhibited at $100 \mu \mathrm{M} \mathrm{H}_{2} \mathrm{O}_{2}$. Maximal speed in fMLP is not significantly different from that in $\mathrm{H}_{2} \mathrm{O}_{2}$.

An alternative method of quantifying neutrophil movement is to measure the forward migration index (FMI), a measure of directionality, that gives the ratio of linear distance travelled in the direction of the $\mathrm{H}_{2} \mathrm{O}_{2}$ gradient to total distance travelled (Fig. 1D). A significant increase in FMI 
was observed at $10 \mathrm{nM} \mathrm{H}_{2} \mathrm{O}_{2}$, and FMI was maximal between $0.1 \mu \mathrm{M}$ and $10 \mu \mathrm{M} \mathrm{H}_{2} \mathrm{O}_{2}$. As in the other assays, directed migration was inhibited at $100 \mu \mathrm{M} \mathrm{H}_{2} \mathrm{O}_{2}$.

All three independent measures agree in showing that $\mathrm{H}_{2} \mathrm{O}_{2}$ is a highly potent neutrophil chemoattractant, from low nanomolar levels up to $10 \mu \mathrm{M}$, and that chemoattraction is inhibited at concentrations of $\mathrm{H}_{2} \mathrm{O}_{2}$ above $10 \mu \mathrm{M}$. A similar concentration-dependence of directed migration in a gradient of $\mathrm{H}_{2} \mathrm{O}_{2}$ was also observed with human blood neutrophils (Fig. 1E).

\section{Sensitivity of neutrophils to single molecules of $\mathrm{H}_{2} \mathrm{O}_{2}$}

The evidence above shows that neutrophils exhibit a clear increase in both movement and direction-finding in concentration gradients as low as $10 \mathrm{nM} \mathrm{H}_{2} \mathrm{O}_{2}$, distributed over the $1 \mathrm{~mm}$ gap between the chemoattractant and DMEM compartments of the ibidi $\mu$-slide. This gradient corresponds to a concentration difference between the leading and trailing edge of a $10 \mu \mathrm{m}$ diameter neutrophil of $100 \mathrm{pM}$, and, assuming that $\mathrm{H}_{2} \mathrm{O}_{2}$ equilibrates rapidly and completely between the extracellular and intracellular spaces, this is a difference on average of around five intracellular molecules of $\mathrm{H}_{2} \mathrm{O}_{2}$ between the leading and trailing halves of the neutrophil (see calculation in legend to Supplementary Materials Fig. 2). The most sensitive neutrophils are therefore able to detect and respond reliably to only a few molecules difference of $\mathrm{H}_{2} \mathrm{O}_{2}$ between the leading and trailing edges. This extraordinary sensitivity to $\mathrm{H}_{2} \mathrm{O}_{2}$ suggests that the detection of $\mathrm{H}_{2} \mathrm{O}_{2}$ is a highly-evolved property, critical for survival.

\section{Neutrophil chemotaxis towards $\mathrm{H}_{2} \mathrm{O}_{2}$ depends on TRPM2}

The TRPM2 ion channel is expressed in neutrophils and is potently activated by $\mathrm{H}_{2} \mathrm{O}_{2}{ }^{12}$, suggesting that it may be a candidate for the sensor of $\mathrm{H}_{2} \mathrm{O}_{2}$. TRPM2 $2^{-/-}$mice are highly susceptible to infection ${ }^{13}$, suggesting that the absence of TRPM2 causes a critical immune system defect. We found that genetic deletion of TRPM2 strongly inhibited $\mathrm{H}_{2} \mathrm{O}_{2}$-dependent neutrophil migration in all three assays (Fig. 1A-D), supporting the idea that TRPM2 is the major physiological sensor of $\mathrm{H}_{2} \mathrm{O}_{2}$ in neutrophils.

\section{Neutrophil chemotaxis towards ADPR depends on TRPM2}

The intracellular $\mathrm{C}$ terminus of TRPM2 contains a nudix hydrolase homology domain (NUDT9$H$ ), named after the mitochondrial ADP-ribose (ADPR) pyrophosphatase NUDT9, to which ADPR binds to activate the ion channel ${ }^{14-21}$. ADPR is known to cross the cell membrane, though the mechanisms are not clear ${ }^{21,22}$ (see also Fig. 3G below). We found that neutrophils responded vigorously to an extracellular gradient of ADPR (Fig. 1F). Migration up a gradient of ADPR was significantly diminished by deletion of TRPM2 (Fig. 1F), showing that neutrophil migration up a gradient of ADPR also depends on TRPM2.

\section{Chemotaxis towards most conventional chemoattractants does not depend on TRPM2}

The marked inhibition of neutrophil migration up gradients of $\mathrm{H}_{2} \mathrm{O}_{2}$ or ADPR, caused by deletion of TRPM2, could be due to an effect of the deletion on migratory ability per se. This possibility is not, however, supported by the observation that TRPM2 deletion does not affect chemotaxis to the known chemoattractants lipopolysaccharide (LPS), C5a and CXCL2 (Fig. 2A). Deletion of TRPM2, however, reduces but does not completely abolish chemotaxis towards the bacterial/mitochondrial peptide fMLP (Fig. 2A), as also noted in all assays shown in Fig. $1 \mathrm{~A}-\mathrm{D}$, suggesting that fMLP exerts its chemotactic effect in part by activating TRPM2.

\section{Neutrophil chemotaxis towards $\mathrm{H}_{2} \mathrm{O}_{2}$ or ADPR is inhibited by blocking TRPM2}

To test further the dependence of neutrophil migration on TRPM2, we examined the effect of pharmacological block of TRPM2 with the inhibitor ACA (N-(p-amylcinnamoyl)anthranilic acid $^{23}$ ). Block of TRPM2 with ACA caused a significant inhibition of chemotaxis in response to both $\mathrm{H}_{2} \mathrm{O}_{2}$ and ADPR (Fig. 2B and Supplementary Materials Fig. 1B), similar in magnitude to the effect of genetic deletion of TRPM2 shown in Fig. 1. Block of TRPM2 with ACA had no effect, however, on chemotaxis towards LPS, C5a and CXCL2, but caused a partial inhibition of migration towards fMLP (Fig. 2B). ACA has off-target actions ${ }^{23}$, but the close resemblance 
to results obtained with genetic deletion of TRPM2 supports the hypothesis that the effects of both genetic deletion and pharmacological block of TRPM2 are due to inhibition of TRPM2 itself and not to an off-target effect on another protein.

Fig. 2C shows similar experiments on human blood neutrophils. All chemoattractants strongly increased $\mathrm{FMI}$ to a similar extent, as was also observed with mouse peritoneal neutrophils (Fig. 2A, B). In Fig. 2D, block of TRPM2 with ACA in human blood neutrophils largely inhibited migration up a gradient of $\mathrm{H}_{2} \mathrm{O}_{2}$ but had no effect on migration up a gradient of IL-8, the human homologue of CXCL2, results closely resembling those in mouse neutrophils (Fig. 2B).

In summary, the results in Fig. 1 and 2 strongly support the hypothesis that TRPM2 is the cellular target that mediates guidance of neutrophils up a gradient of $\mathrm{H}_{2} \mathrm{O}_{2}$.

\section{Variability in values of FMI}

There is a range of sensitivities to $\mathrm{H}_{2} \mathrm{O}_{2}$ amongst neutrophils, with some showing strongly directional migration up a gradient of $\mathrm{H}_{2} \mathrm{O}_{2}$ (FMI close to 1.0), while others show lower, or even absent, directional motility (Supplementary Materials Fig. 2 and Supplementary video 1). The variability in values for FMI amongst individual neutrophils explains why the mean FMI does not typically exceed a value of around 0.6 , when a value of 1.0 would be expected if all neutrophils migrated in a straight line. The proportion of highly mobile to less mobile neutrophils was found to be variable in different experiments (Supplementary Materials Fig. 2). The reason for this diversity in response is unknown but could be related to the age or condition of different neutrophils in the pool.

We tested whether the apparently lower maximal values of FMI in some experiments (for example with ADPR, Fig. 1F) was due to a real difference or simply reflected variability between different neutrophil samples. Fig. 2A-C show that maximal FMI values are in fact not statistically different amongst $\mathrm{H}_{2} \mathrm{O}_{2}$, ADPR, LPS, C5a CXCL2 and fMLP when measured on a single neutrophil sample.

\section{Neutrophil migration to $\mathrm{H}_{2} \mathrm{O}_{2}$ depends strongly on temperature}

TRPM2 is a member of the large TRP family of ion channels, and like several other members of this family, is strongly activated by increasing temperatures within the physiological range $\mathrm{e}^{20,24-26}$. Fig. $3 \mathrm{~A}$ shows that neutrophil migration towards very low concentrations of $\mathrm{H}_{2} \mathrm{O}_{2}$ is potently enhanced by small increases of temperature and that the effect of temperature is abolished by deletion of TRPM2. The effect of temperature is particularly prominent in a gradient of $1 \mathrm{nM} \mathrm{H}_{2} \mathrm{O}_{2}$, when an elevation from $37^{\circ} \mathrm{C}$ to $39^{\circ} \mathrm{C}$, corresponding to a mild fever, enhances the ability of neutrophils to migrate up a gradient of $\mathrm{H}_{2} \mathrm{O}_{2}$ from an FMI of $0.052 \pm$ 0.028 to $0.277 \pm 0.059$, a 5.3-fold increase. By contrast, the effect of temperature on migration towards the conventional chemoattractants CXCL2, C5a and LPS is much less marked (Fig. $3 \mathrm{~B}-\mathrm{D})$. The strong temperature dependence of neutrophil migration towards $\mathrm{H}_{2} \mathrm{O}_{2}$ provides further support for a critical role of TRPM2 in neutrophil migration in response to $\mathrm{H}_{2} \mathrm{O}_{2}$, and moreover suggests a reason why fever may be beneficial in fighting infection, because an elevation of temperature by only $2^{\circ} \mathrm{C}$, corresponding to a mild fever, gives a five-fold increase in neutrophil migratory ability towards low levels of $\mathrm{H}_{2} \mathrm{O}_{2}$.

\section{Temperature and chemoattractants cause elevations in intracellular calcium}

TRPM2 is permeable to calcium ions ${ }^{12}$, like other members of the TRP family ${ }^{27,28}$, suggesting that the striking dependence of neutrophil migration on temperature may be due to a calcium influx through activated TRPM2 ion channels. Fig. 3E shows that elevations of temperature in the physiological range (from $37^{\circ} \mathrm{C}$ to $41^{\circ} \mathrm{C}$ ) induce an intracellular calcium increase, and that low concentrations of $\mathrm{H}_{2} \mathrm{O}_{2}$ ( $1 \mathrm{nM}$ and $10 \mathrm{nM}$ ) enhance the amplitude of the calcium increase and lower its temperature threshold. Deletion of TRPM2 abolishes the thermally-induced elevations of calcium (Fig. 3F). The strong temperature-dependence of calcium influx through TRPM2 supports the hypothesis that a calcium influx through TRPM2 underlies the striking temperature-sensitivity of neutrophil migration driven by $\mathrm{H}_{2} \mathrm{O}_{2}$ (Fig. 3A). The results also 
support the idea that calcium influx through TRPM2 may be a driver of neutrophil motion, for which further evidence is presented below.

We next examined whether the agonists $\mathrm{H}_{2} \mathrm{O}_{2}$, ADPR and fMLP, whose effect on neutrophil migration depends on activation of TRPM2 (see above), also induce a calcium influx. Fig. 3G and $\mathrm{H}$ show that in all cases these agonists cause an elevation of intracellular calcium, from the resting level of around $100 \mathrm{nM}$ to $500 \mathrm{nM}$, and that the increase is dependent on TRPM2. There was a significant delay between application of $\mathrm{H}_{2} \mathrm{O}_{2}$ or ADPR and activation of calcium influx, consistent with an intracellular site of action for both agonists. $\mathrm{H}_{2} \mathrm{O}_{2}$ is able to cross the cell membrane through aquaporins ${ }^{29}$, and ADPR is also known to cross the neutrophil cell membrane, though the mechanisms are not clear ${ }^{21,22}$. There was a rapid drop in intracellular calcium when external calcium was removed (Fig. 3G, left-hand panel), showing that activation of TRPM2 causes an influx of calcium from the extracellular solution.

\section{Leading-edge calcium pulses in $\mathrm{H}_{2} \mathrm{O}_{2}$ and ADPR are driven by TRPM2}

The results above suggest that preferential activation of TRPM2 channels by elevated levels of $\mathrm{H}_{2} \mathrm{O}_{2}$ at the neutrophil leading edge could cause a localised calcium influx that guides neutrophil chemotaxis by coupling to the motile machinery. We used calcium imaging of migrating neutrophils and we observed that an elevated intracellular calcium concentration at the neutrophil leading edge is indeed seen during movement of a neutrophil up a gradient of $\mathrm{H}_{2} \mathrm{O}_{2}$ (Fig. 4A, left panel). Leading-edge intracellular calcium elevations were seen in all migrating neutrophils, and they had a pulsatile appearance for which the name "calcium pulse" seemed appropriate (see for example Supplementary video 2). The calcium pulse is most prominent at the base of the pseudopodium, but in some images it can be seen also invading the advancing pseudopodium itself (Fig. 4B, C and Fig. 5A, B). Genetic deletion of TRPM2 abolishes both calcium pulses and cell migration (Fig. 4A, centre, and Fig. 4B - E). At high concentrations of $\mathrm{H}_{2} \mathrm{O}_{2}$, maximal activation of TRPM2 in all parts of the cell membrane means that a uniformly high level of calcium floods the cell and neutrophil migration is abolished (Fig. $4 \mathrm{~A}$, right).

Pharmacological block of TRPM2 with the inhibitor $\mathrm{ACA}^{30}$ has a similar effect to genetic deletion of TRPM2 in inhibiting calcium pulses and neutrophil chemotaxis towards $\mathrm{H}_{2} \mathrm{O}_{2}$ and ADPR (Fig. 4B - E). Both calcium pulses and neutrophil movement are also abolished by withdrawal of extracellular calcium (Fig. 4B, D), consistent with an influx of calcium from the external medium acting as a trigger for the generation of intracellular calcium pulses. Lowering the temperature to $33^{\circ} \mathrm{C}$, which strongly inhibits neutrophil motility (Fig. $3 \mathrm{~A}$ ), also inhibits the generation of calcium pulses (Fig. 4B, D and Supplementary Materials Fig. 4B). These parallel observations using a range of approaches support the idea that leading-edge calcium pulses in both $\mathrm{H}_{2} \mathrm{O}_{2}$ and ADPR are generated by an influx of calcium through TRPM2, and that calcium pulses are coupled to migration.

\section{Leading-edge calcium pulses in classical chemoattractants are not driven by TRPM2}

Fig. 5B and Supplementary Materials Fig. 5 show that leading-edge calcium pulses, similar to those observed in $\mathrm{H}_{2} \mathrm{O}_{2}$ and ADPR, are also seen in gradients of the chemoattractants CXCL2, LPS and C5a. These observations suggest that calcium pulses "steering" neutrophil chemotaxis, by determining the future direction of establishment of pseudopodia, may be a universal mechanism. Block of TRPM2 with ACA has no effect on calcium pulses in the classical chemoattractants CXCL2, LPS and C5a. Together with the data in Fig. 2 showing the lack of effect of TRPM2 deletion or block on neutrophil migration to classical chemoattractants, these experiments show that neither the generation of leading-edge calcium pulses nor neutrophil migration in these chemoattractants is driven by a TRPM2dependent mechanism. 


\section{Signalling pathways determining neutrophil motility}

There have been several proposals regarding the mechanisms that couple chemoattractants to the intracellular motile machinery of immune cells, including activation of PI3K to generate PIP3 at the neutrophil leading edge, leading to activation of Rac ${ }^{1,31-34}$; or, in the case of chemoattraction by $\mathrm{H}_{2} \mathrm{O}_{2}$, oxidative modulation of cysteine residues present in the $\mathrm{Src}$ family tyrosine kinase $/ y n^{9,11}$. Fig. 5 and Supplementary Materials Figs. 5 and 6 investigate potential signalling pathways involved in neutrophil chemotaxis. PP2, a potent inhibitor of Src family kinases (SFK), caused only partial inhibition of motility in a gradient of $\mathrm{H}_{2} \mathrm{O}_{2}$ (Fig. 5A, C and Supplementary Materials Fig. 6) suggesting that a member of the Src kinase family modulates $\mathrm{H}_{2} \mathrm{O}_{2}$-directed motility but is not essential for generating movement. PP2 also partially inhibited the amplitude of calcium pulses (Fig. 5A, C), consistent with a SFK member acting upstream of the generation of calcium pulses. Interestingly, PP2 had no effect on either neutrophil motility nor generation of calcium pulses in gradients of the classical chemoattractants CXCL2, LPS or C5a (Fig. 5B, D and Supplementary Materials Fig. 5, 6), showing that the effect of SFK inhibition is specific to the $\mathrm{H}_{2} \mathrm{O}_{2}$ /TRPM2 mechanism. One possibility is that lyn may promote trafficking of TRPM2 to the surface membrane, and thus inhibition of lyn would reduce the calcium influx triggered when TRPM2 is activated by $\mathrm{H}_{2} \mathrm{O}_{2}$. An SFK member has been shown to play a similar role in promoting trafficking of TRPV1 to the neuronal cell surface membrane ${ }^{35}$.

PI3K and Rac have also been suggested as initiators of neutrophil chemotaxis ${ }^{1,31-34}$. However, the PI3K inhibitor wortmannin and the Rac inhibitor EHT1864 only partially inhibited neutrophil chemotaxis in response to $\mathrm{H}_{2} \mathrm{O}_{2}, \mathrm{CXCL} 2$, LPS and C5a (Fig. 5 and Supplementary Materials Fig. 5,6 ). In the case of chemotaxis to $\mathrm{H}_{2} \mathrm{O}_{2}$, the residual motility in the presence of the PI3K and Rac blockers was completely inhibited by the TRPM2 blocker ACA (Supplementary Materials Fig. 6A). The PI3K and Rac inhibitors also reduced the amplitudes of leading-edge calcium signals, suggesting that $\mathrm{PI} 3 \mathrm{~K}$ and Rac play a modulatory role in the pathways upstream of the generation of calcium pulses, but that the amplitude of calcium pulses is the primary event controlling motility in response to all chemoattractants.

\section{Calcium pulses determine the direction of neutrophil chemotaxis}

Increases in intracellular calcium in neutrophils and other immune cells have been suggested to be a consequence of cell movement, as might arise if a calcium increase was required to retract the trailing edge of the cell ${ }^{36}$, or because an interaction between cell and substrate triggers calcium entry caused by the movement itself 37,38 . In these scenarios, the calcium increase would be expected to follow the movement, while if the calcium pulse directs the movement it would be expected to precede it. For this reason we investigated whether a change in the cellular location of calcium pulses precedes a subsequent change in the direction of cell migration (calcium drives migration), or whether a change in the direction of migration precedes a change in location of calcium pulses (migration drives calcium). Neutrophils in the absence of a chemotactic gradient still exhibit calcium pulses, which change cellular location at intervals, and also exhibit random migration (See Supplementary video 2), providing a useful way of distinguishing these two possibilities.

We quantified the angle between the geometric centre of the cell and the centre of the calcium pulse occurring at the same moment (calcium vector angle, Fig. 6A) and compared this angle with the angle between the geometric centre of a neutrophil at the moment of the calcium pulse and at different times as the cell advances (movement vector angle, Fig. 6A). In the case of the neutrophil shown in Fig. 6B and Supplementary Video File 2, the calcium vector turns from an overall upward direction to an overall downward direction halfway through the recording (shown by a star in Fig. 6B and 6C). As is also visible in Supplementary Video File 2 , the change in cell direction follows the change in calcium signal direction with a significant delay.

The calcium vector connecting the cell geometric centre and the calcium pulse is measured at a given moment (blue trace in Fig. 6C), but the movement vector (orange trace) can refer 
to the cell position at a variable past or future time. Fig. $6 \mathrm{C}$ shows that a lag of $+75 \mathrm{~s}$ between calcium vector and movement vector best describes the moment at which the movement vector begins to reverse in response to the abrupt change in the direction of the calcium vector. This positive delay is consistent with calcium driving the direction of movement, while a negative delay gives a poor fit (shown for a -50s delay). These results are consistent with a change in calcium pulse location driving a change in movement, with a delay of around $75 \mathrm{~s}$, and does not agree with the idea that movement might cause (i.e. anticipate) the calcium pulse. There is a further significant delay (half-time $\sim 83 \mathrm{~s}$ ) before the cell movement fully aligns with the new direction of the calcium vector (see middle panel in Fig. 6C), giving a total time lag between change of the direction of the calcium pulse and half-time of alignment of movement with the new calcium pulse location of 158s. Two further neutrophils analysed in the same way gave similar delays, with total half-time for the alignment of cell movement to a change in calcium direction of $146 \mathrm{~s}$ and $164 \mathrm{~s}$. The neutrophil movement therefore reacts to a change in the direction of a calcium pulse with a surprisingly long delay, with total half-time of around 160s, or almost 3 minutes.

Finally, Fig. 6D shows a comparison between the external $\mathrm{H}_{2} \mathrm{O}_{2}$ concentration surrounding a cell migrating half-way up a $10 \mathrm{nM}$ gradient over $1 \mathrm{~mm}$, and the internal calcium concentration measured with fura-2. The calcium gradient is very much steeper than the $\mathrm{H}_{2} \mathrm{O}_{2}$ gradient, showing that there must be a powerful non-linear amplification process that converts the gentle $\mathrm{H}_{2} \mathrm{O}_{2}$ gradient into the strongly enhanced calcium signal seen at the cell leading edge.

\section{Discussion}

The work described here confirms previous studies showing that $\mathrm{H}_{2} \mathrm{O}_{2}$ is a potent neutrophil chemoattractant both in vitro ${ }^{2}$ and in vivo ${ }^{3}$. We demonstrate an essential role for the TRPM2 ion channel in directing neutrophil chemotaxis towards $\mathrm{H}_{2} \mathrm{O}_{2}$. We propose that preferential activation of TRPM2 by the higher levels of $\mathrm{H}_{2} \mathrm{O}_{2}$ at the neutrophil leading edge causes a calcium influx, triggering amplified leading-edge calcium pulses that determine the direction of extension of pseudopodia and therefore of future neutrophil motion. There is a significant delay, of around 160s, between a change of location of a calcium pulse and the half-time of response of the neutrophil direction, in striking contrast to the millisecond reaction time of many other calcium-driven cellular processes such as skeletal muscle contraction or synaptic vesicle exocytosis.

We find that neutrophils are guided by $\mathrm{H}_{2} \mathrm{O}_{2}$ over four orders of magnitude of concentration, from $1 \mathrm{nM}$ to $10 \mu \mathrm{M}$. Higher concentrations of $\mathrm{H}_{2} \mathrm{O}_{2}(>10 \mu \mathrm{M})$ inhibit chemotaxis and cause an elevated calcium concentration throughout the cell. In agreement, previous studies have also found inhibition of chemotaxis in neutrophils and lymphocytes at levels of $\mathrm{H}_{2} \mathrm{O}_{2}$ above $10 \mu \mathrm{M}^{39,40}$. A probable cause of the inhibition of chemotaxis at higher $\mathrm{H}_{2} \mathrm{O}_{2}$ is loss of the differential intracellular calcium gradient necessary for cell guidance, as shown in Fig. 4A.

Neutrophil guidance towards conventional chemoattractants such as LPS, C5a or CXCL2 is independent of TRPM2, but similar leading-edge calcium pulses are still observed, suggesting that guidance by calcium pulses is a universal mechanism. Signalling from the G-protein coupled receptors activated by conventional chemoattractants to intracellular calcium stores is a likely mechanism ${ }^{41,42}$. An interesting exception to the TRPM2-independence of conventional chemoattractants is chemotaxis towards fMLP, which is partially inhibited by either pharmacological block or genetic deletion of TRPM2. A possible explanation may lie in the recently-discovered physical interaction between TRPM2 and FPR1, the receptor for fMLP ${ }^{40}$.

Previous studies of the involvement of TRPM2 in neutrophil chemotaxis have come to contradictory conclusions. Yamamoto et $\mathrm{al}^{43}$ found that deletion of TRPM2 decreased neutrophil migration in response to an inflammatory supernatant formed by activated neutrophils in vitro and also decreased movement to areas of inflammation in vivo. In support, 
Hiroi et $\mathrm{al}^{44}$ found that neutrophil invasion following myocardial ischaemia was lowered in $\mathrm{Trpm}^{-/-}$mice. Wang et $\mathrm{al}^{40}$, in contrast, found that deletion of TRPM2 promotes chemotaxis both in vitro and in vivo and they propose that TRPM2 generates a "stop" signal to halt neutrophil migration in the vicinity of pathogens. In the present study we show both in vitro and in vivo that neutrophil motility is potently promoted by low levels of $\mathrm{H}_{2} \mathrm{O}_{2}$, and that motility is inhibited, both in vivo and in vitro, by either pharmacological inhibition or genetic deletion of TRPM2. Thus, at low concentrations of $\mathrm{H}_{2} \mathrm{O}_{2}$, TRPM2 mediates a powerful chemoattractant mechanism. In addition, we find that high concentrations of $\mathrm{H}_{2} \mathrm{O}_{2}$ (above $10 \mu \mathrm{M}$ ) inhibit neutrophil motility, which may be critical in providing a "stop" mechanism in the vicinity of pathogens. We show that inhibition is due to a rise of the internal calcium level throughout the cell when TRPM2 channels are maximally activated by $\mathrm{H}_{2} \mathrm{O}_{2}$, thus flooding the cell with calcium and abolishing the internal calcium gradient necessary for neutrophil navigation.

The ratio between calcium at the leading and trailing edge of an advancing neutrophil is much greater than the ratio between $\mathrm{H}_{2} \mathrm{O}_{2}$ concentrations (Fig. 6D), suggesting that a process of non-linear amplification enhances the leading-edge calcium signal. One likely possibility for such a mechanism is the highly non-linear process of calcium-induced calcium release from subcellular stores $21,22,41,42,45$.

A scheme consistent with the work reported here is shown in Supplementary Materials Fig. 8. In a gradient of $\mathrm{H}_{2} \mathrm{O}_{2}$, preferential activation of TRPM2 ion channels at the leading edge causes an influx of calcium from the extracellular solution, triggering calcium-induced calcium release from intracellular stores. The Src family kinase lyn modulates this pathway at an early stage, perhaps by regulating trafficking of TRPM2 ion channels to the surface membrane. The intracellular signalling molecules PI3K and Rac, which have been proposed as drivers of chemotaxis, do not appear to play a direct role in chemotaxis, but instead fine-tune motility to all chemoattractants by regulating a step common to all chemoattractants, for example refilling of the intracellular calcium stores, and thus modulate the amplitude of the leading-edge calcium pulses.

Some studies have found no evidence for calcium gradients in neutrophils during chemotaxis $^{38,46}$, though others have obtained evidence that leading-edge calcium signals play a critical role in chemotaxis of many different cell types ${ }^{47,48}$. In the present work, we observed leading-edge calcium signals in all motile neutrophils in vitro. Interestingly, leading-edge calcium signals have also recently been detected in migrating neutrophils in vivo ${ }^{49}$. These authors find that neutrophils can be guided in vivo by expressing TRPV1 and then imposing a directional gradient of the TRPV1 agonist capsaicin ${ }^{49,50}$. This work supports the idea that a TRP channel alone can mediate neutrophil guidance, but it does not identify the responsible TRP isoform. Here we identify TRPM2 as the ion channel mediating physiological neutrophil guidance towards a source of $\mathrm{H}_{2} \mathrm{O}_{2}$. TRPM2 may be an interesting future drug target, for instance in controlling excess neutrophil invasion in conditions such as sepsis.

Neutrophils are able to navigate up a gradient of $\mathrm{H}_{2} \mathrm{O}_{2}$ in which there is an average difference of only a few molecules of intracellular $\mathrm{H}_{2} \mathrm{O}_{2}$ between the leading and trailing halves of the cell. This extraordinary sensitivity suggests that navigation towards $\mathrm{H}_{2} \mathrm{O}_{2}$ is vital for mammalian survival and has been highly honed by evolution. The strong temperature dependence of TRPM2 activation ${ }^{20,24-26}$ suggests a novel function for fever: by enhancing TRPM2 activation, fever potently enhances the sensitivity to a gradient of $\mathrm{H}_{2} \mathrm{O}_{2}$, thereby enhancing neutrophil guidance and promoting the detection and killing of invading pathogens. $\mathrm{H}_{2} \mathrm{O}_{2}$ may therefore play a more critical role than conventional cytokines in the early phase of the response of the innate immune system to tissue damage or pathogen attack. 


\section{Figure 1}

A

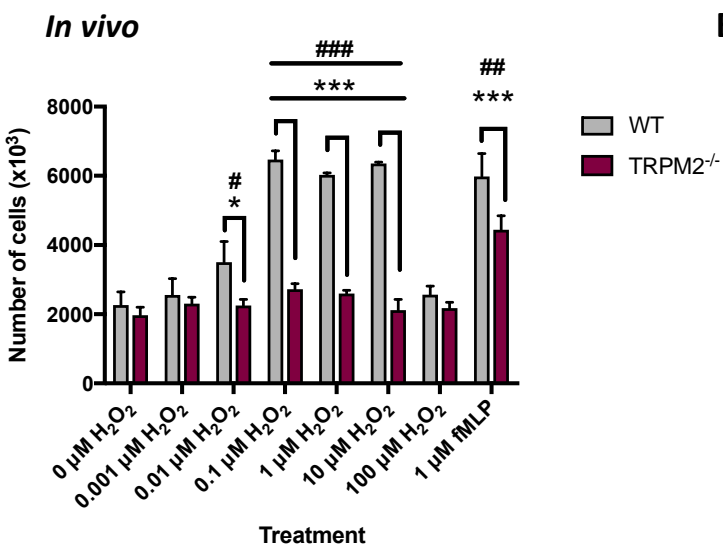

C

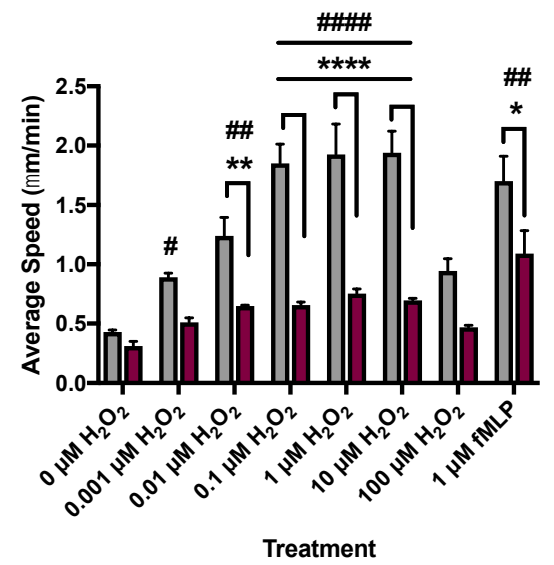

Ibidi $\mu$-slide, human neutrophils

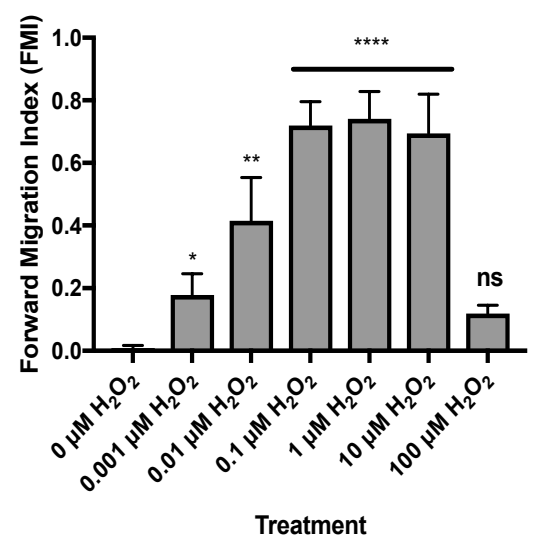

D
B Boyden chamber
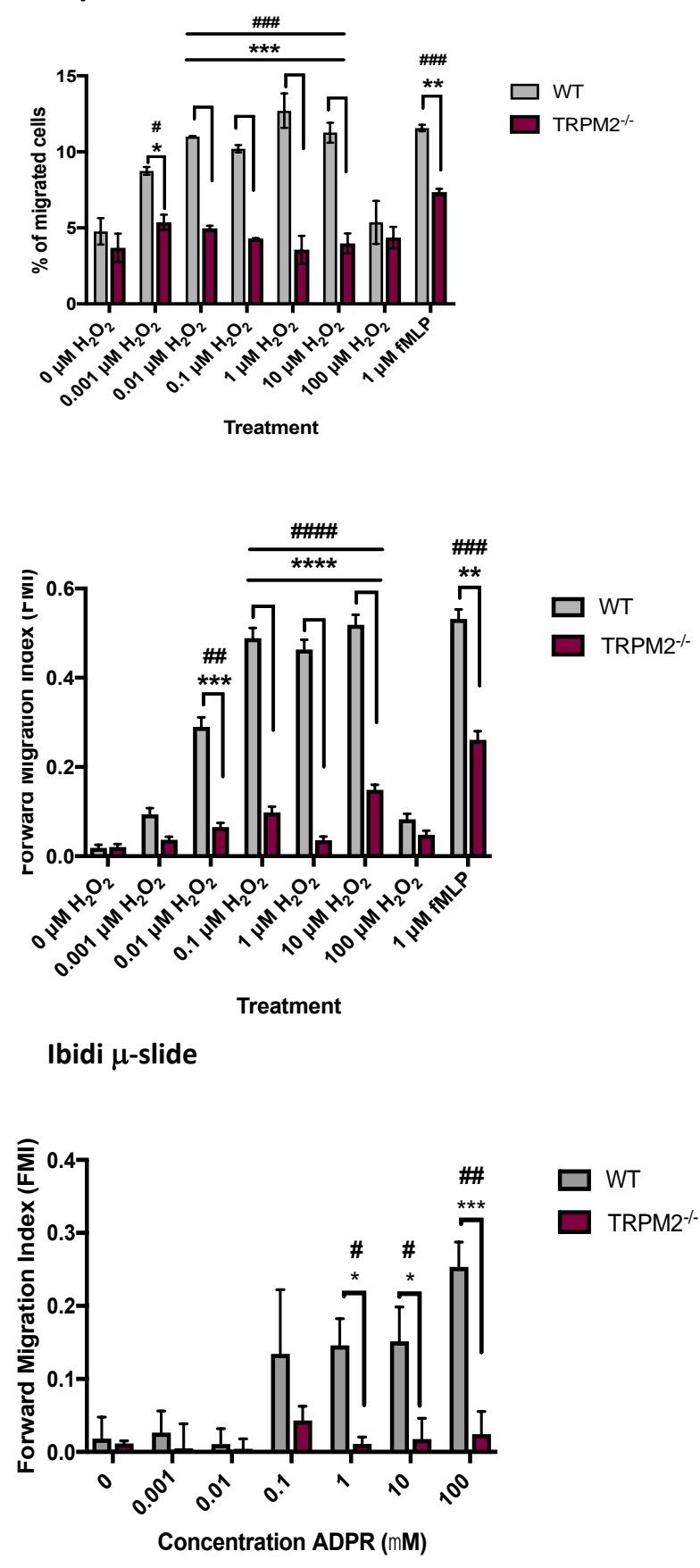


\section{Fig. 1. Neutrophil chemoattraction by $\mathrm{H}_{2} \mathrm{O}_{2}$ depends on TRPM2}

A. Chemotaxis of neutrophils into the peritonea of WT and TRPM2 $\%$ mice following i.p. injection of $\mathrm{H}_{2} \mathrm{O}_{2}$. Direct injection of $0-100 \mu \mathrm{M} \mathrm{H}_{2} \mathrm{O}_{2}$ or $1 \mu \mathrm{M} \mathrm{fMLP}$ into the peritonea of WT and TRPM $2 \%$ mice (see Methods for details) elicited movement of total number of cells per peritoneum (ordinate). Time course of chemotaxis was determined in WT mice as shown in Supplementary Materials Fig. 1. Maximal chemotaxis in WT mice calculated from the average of 3 points between 60 and $120 \mathrm{~min}$. For $\mathrm{TRPM}^{-/-}$mice, chemotaxis was measured only at the $90 \mathrm{~min}$ point. Each bar shows mean \pm SEM ( $n=3$ mice).

B. Boyden chamber assay of mouse neutrophil chemotaxis. Each bar shows mean \pm SEM \% migration from $n=4$ mice $(n=8$ for $0 \mu M)$.

C. In vitro ibidi $\mu$-slide chemotaxis chamber assay using mouse neutrophils. Average speed of neutrophil migration, calculated for each neutrophil as path length of distance travelled divided by time. Each bar shows mean \pm SEM of $n=4$ mice.

D. In vitro ibidi $\mu$-slide chemotaxis chamber assay using mouse neutrophils. Forward migration index (FMI) is distance migrated in direction of gradient of $\mathrm{H}_{2} \mathrm{O}_{2}$ or $\mathrm{FMLP}$ divided by total distance travelled, from same experiments as shown in C. Note that concentrations of $\mathrm{H}_{2} \mathrm{O}_{2}$ in the nanomolar range are able to increase both speed and directionality of neutrophil migration, and that migration is inhibited at high concentrations of $\mathrm{H}_{2} \mathrm{O}_{2}(>10 \mu \mathrm{M})$. Distribution of values of $\mathrm{FMI}$ shown in Supplementary Materials Fig. 2. Each bar shows mean $\pm S E M$ of $n=4$ mice.

E. In vitro ibidi $\mu$-slide chemotaxis chamber assay using neutrophils isolated from human volunteer blood. FMI of human blood neutrophils shows similar dependence on concentration of $\mathrm{H}_{2} \mathrm{O}_{2}$ to mouse peritoneal neutrophils (compare with $D$ ). Each bar shows mean \pm SEM of $n=3$ individual human neutrophil samples.

F. Extracellular ADPR is a potent chemoattractant dependent on TRPM2 activation. WT mouse neutrophils showed significantly increased FMI compared to TRPM $2^{-/-}$ neutrophils in response to $1-100 \mu \mathrm{M}$ ADPR. Each bar shows mean \pm SEM from $n=3$ mice.

Statistical analysis: For comparison with $0 \mathrm{H}_{2} \mathrm{O}_{2}$ : \#, p<0.05, \#\#, $\mathrm{p}<0.01$, \#\#\#, $\mathrm{p}<0.001$, \#\#\#\#, $p<0.0001$ (One-way ANOVA and Tukey-Kramer post-hoc test). For comparison with TRPM2 ${ }^{-/-}$ (except in E): ${ }^{*}, \mathrm{p}<0.05, * *, \mathrm{p}<0.01, * * *, \mathrm{p}<0.001, * * * *, \mathrm{p}<0.0001$ (Two-way ANOVA and Bonferroni's post-hoc test). 


\section{Figure 2}

A

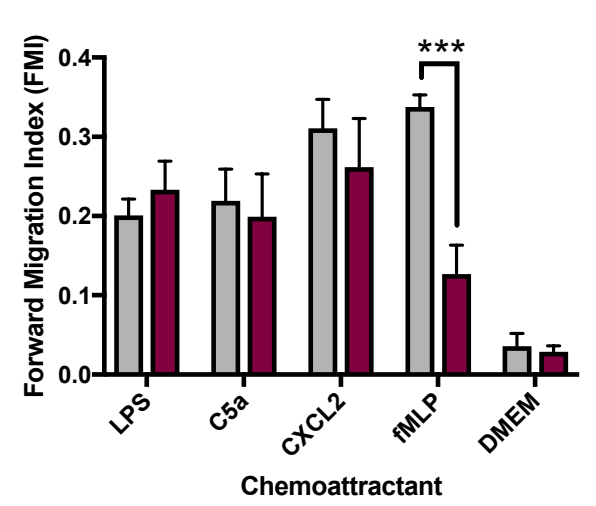

C

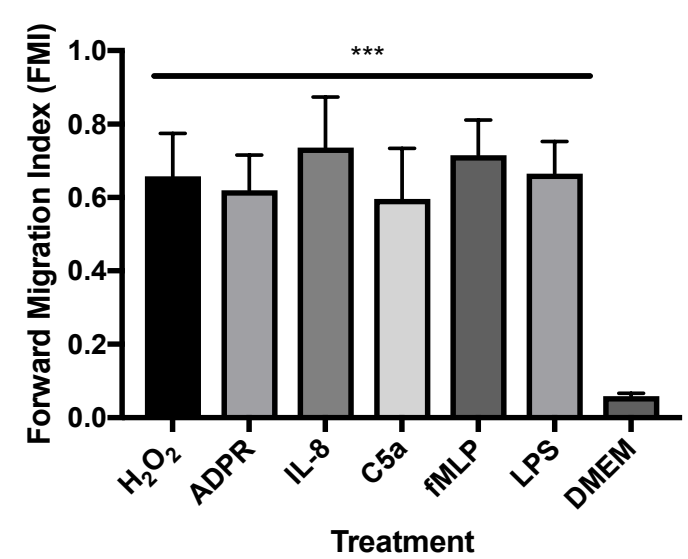

B

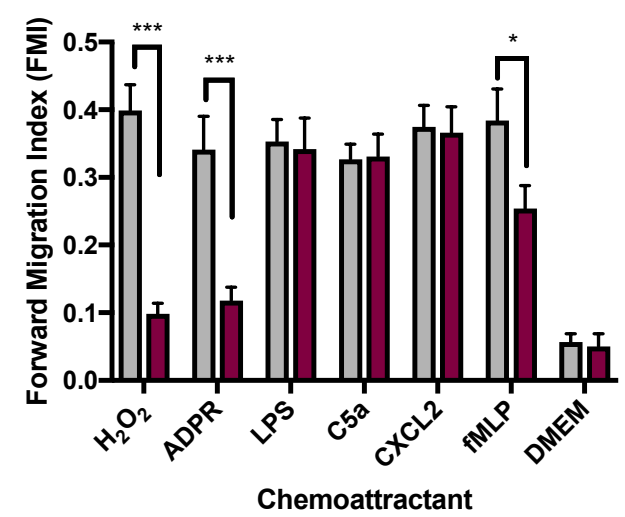

$\square$ WT

$\square \mathrm{WT}+\mathrm{ACA}$

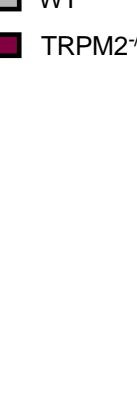

D

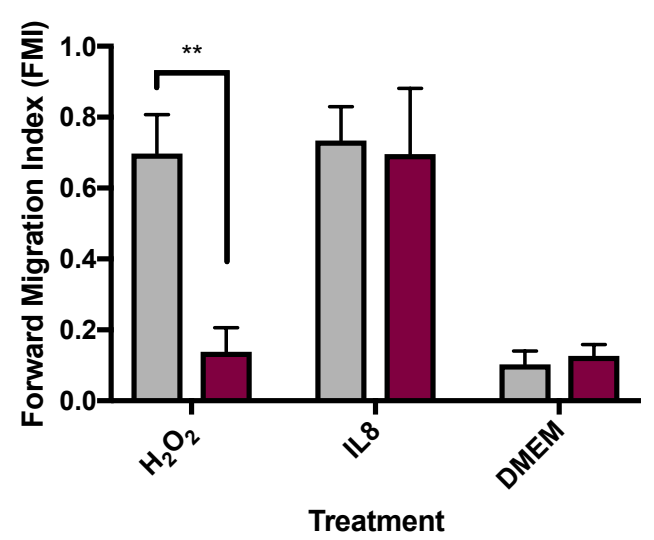


Fig. 2: Dependence on TRPM2 of migration towards neutrophil chemoattractants.

A. Effect of genetic deletion of TRPM2 on mouse neutrophil migration. Forward migration index (FMI) in response to gradient of lipopolysaccharide (LPS, $50 \mathrm{ng} / \mathrm{ml}$ ), C5a (10 nM), CXCL2 (10 nM) and fMLP (1 $\mu \mathrm{M})$, all over $1 \mathrm{~mm}$. No significant difference in FMI of WT and TRPM2 $2^{--}$neutrophils in response to LPS, C5a or CXCL2, but neutrophil migration to fMLP was significantly inhibited by TRPM 2 deletion.

B. Effect of pharmacological block of TRPM2 with ACA (N-(p-amylcinnamoyl)anthranilic acid, $10 \mu \mathrm{M})$ on mouse neutrophil migration. FMI in gradient of $\mathrm{H}_{2} \mathrm{O}_{2}(0.01 \mu \mathrm{M})$, ADPR $(100 \mu \mathrm{M})$ and other chemoattractants as in A.

C. Human blood neutrophil FMI in response to gradients of chemoattractants as follows, all over 1mm: $\mathrm{H}_{2} \mathrm{O}_{2}(0.01 \mu \mathrm{M})$, ADPR (100 $\left.\mu \mathrm{M}\right)$, IL8 (10nM), C5a (10 nM), fMLP $(1 \mu \mathrm{M})$ and LPS (50 ng/ml).

D. Inhibition of human blood neutrophil FMI by TRPM2 blocker ACA (10 $\mu \mathrm{M})$. Gradients over $1 \mathrm{~mm}: \mathrm{H}_{2} \mathrm{O}_{2}(0.01 \mu \mathrm{M})$, IL8 (10nM).

Statistical analysis: Mean \pm SEM, independent samples from $n=3$ mice or humans in each panel. A, B, D: pairwise t-test comparing WT to TRPM $2^{-/-}$or ACA. C: One-way ANOVA and Tukey-Kramer post-hoc test compared to DMEM. ${ }^{*}, \mathrm{p}<0.05 ;{ }^{* *}, \mathrm{p}<0.01 ;{ }^{* * *} \mathrm{p}<0.001 ;{ }^{* * * *}$, $p<0.0001$, difference non-significant if not stated. 


\section{Figure 3}

A

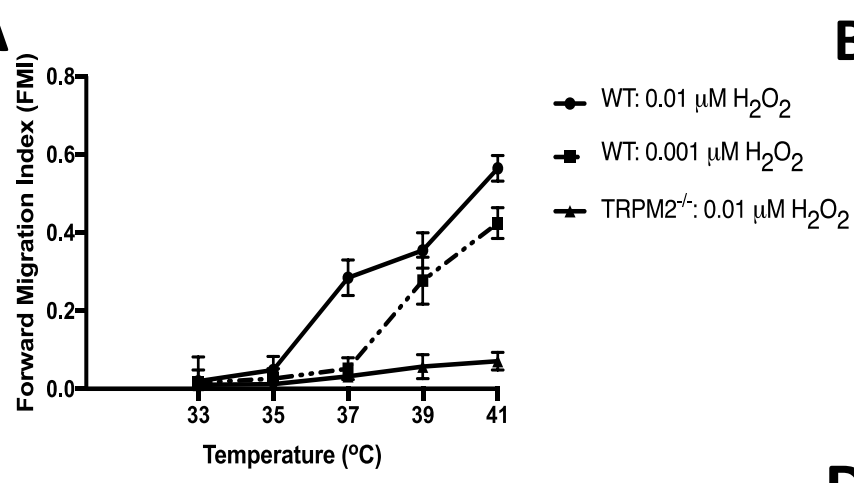

C

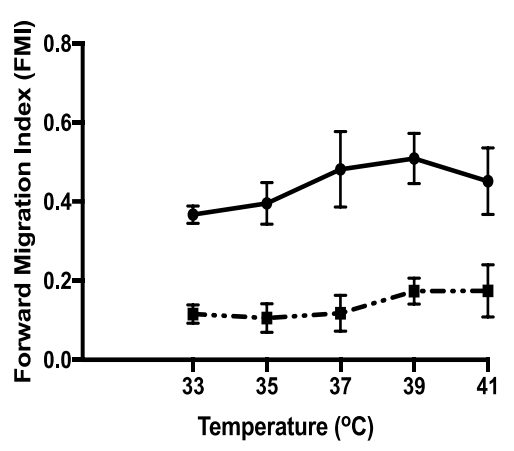

$\mathbf{E}$
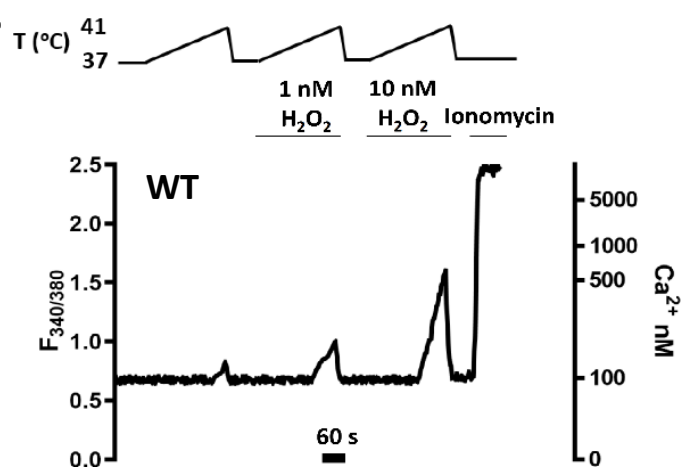

$\mathbf{F}_{\mathrm{T}}$
B

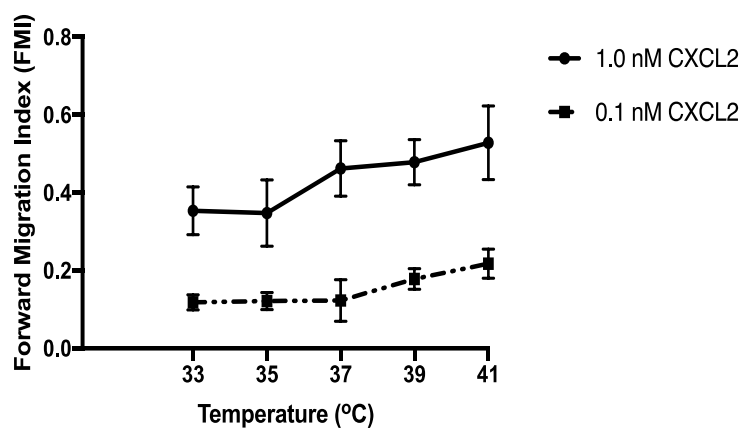

$\rightarrow 10 \mathrm{nMC5a}$

$-1.0 \mathrm{nMC5a}$
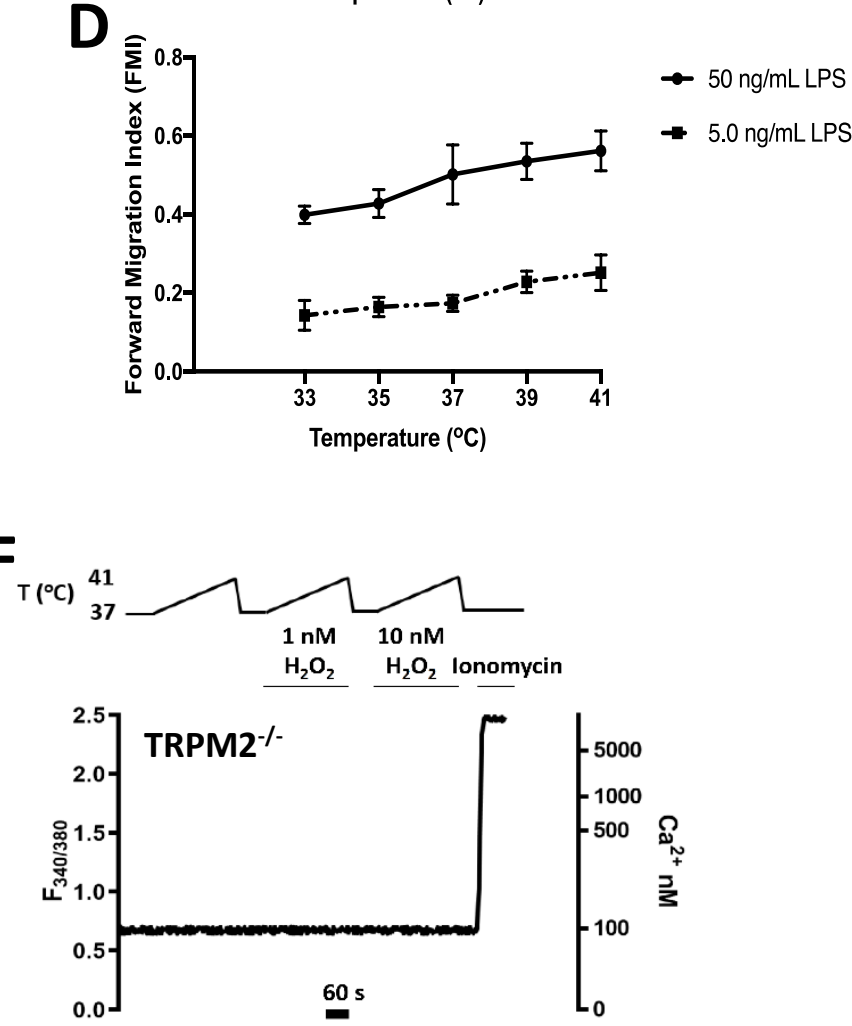

G $\frac{\mathrm{H}_{2} \mathrm{O}_{2}}{\mathrm{OC}^{2+}}$ Ionomycin
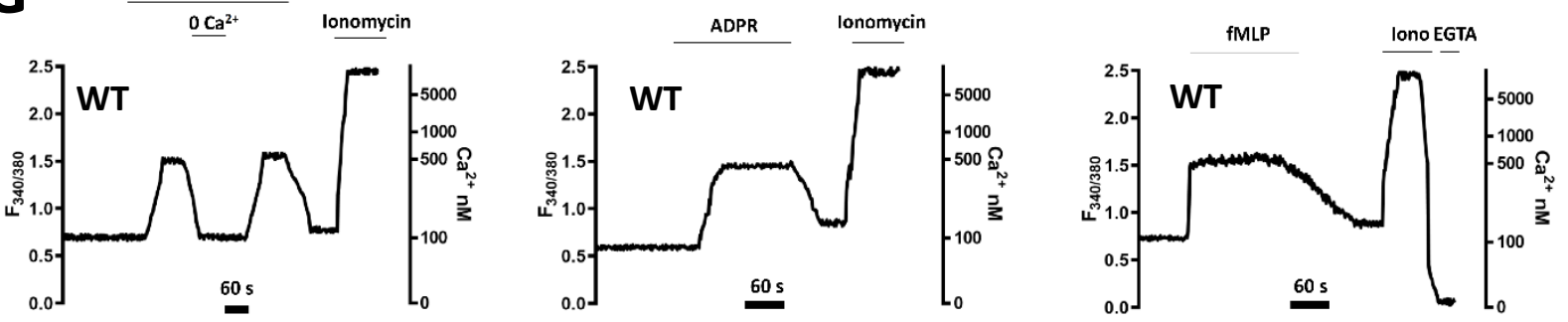

H
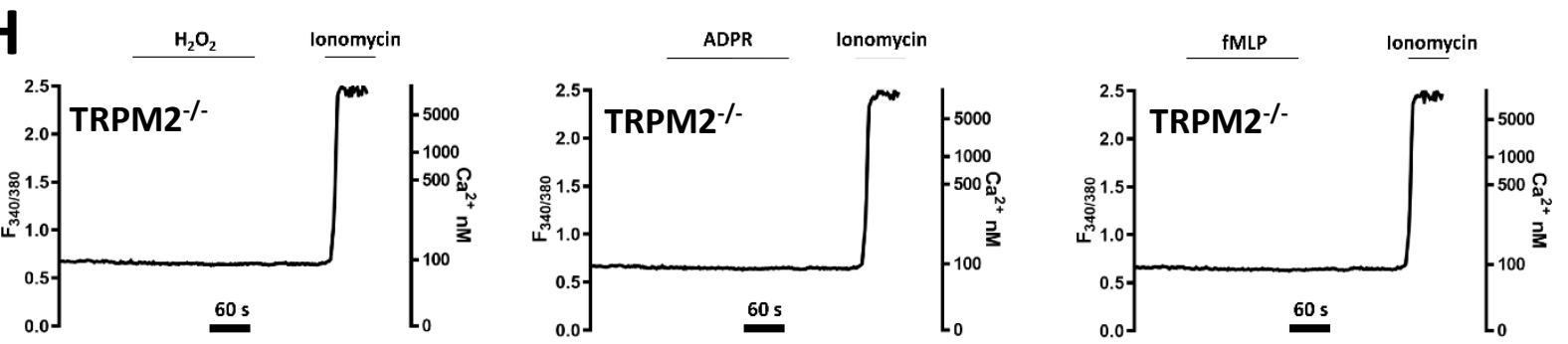
Fig. 3. A-D: Dependence on temperature and TRPM2 of forward migration index (FMI) of neutrophil chemotaxis. Neutrophil migration in response to $\mathrm{H}_{2} \mathrm{O}_{2}$ tracked for $2 \mathrm{~h}$ in the ibidi $\mu$-slide chemotaxis system using live-cell time-lapse microscopy. FMI, as a function of temperature, measured with the following genotypes and chemoattractants: $(A)$ WT, to $0.001 \mu \mathrm{M}$ and $0.01 \mu \mathrm{M} \mathrm{H}_{2} \mathrm{O}_{2}$; $\mathrm{TRPM}^{\%} \%$, to $0.01 \mu \mathrm{M} \mathrm{H}_{2} \mathrm{O}_{2}$; (B) WT, to 0.1nM and 1nM CXCL2; (C) WT, to $1.0 \mathrm{nM}$ and $10 \mathrm{nM}$ C5a; (D) WT, to 5.0 and $50 \mathrm{ng} / \mathrm{ml}$ LPS. Concentrations of conventional chemoattractants giving sub-maximal and near-maximal migration determined in separate experiments (see Supplementary Materials Fig. 3). Each point shows mean \pm SEM, $n=3$ separate experiments using neutrophils from 3 mice.

E, F: Potentiation of calcium entry through TRPM2 by temperature and $\mathrm{H}_{2} \mathrm{O}_{2}$. (E) Increase of [Ca $]_{i}$ in response to a temperature ramp from $37^{\circ} \mathrm{C}$ to $41^{\circ} \mathrm{C}$ in neutrophils from WT mice. Threshold for [Ca] increase was $40.2^{\circ} \mathrm{C}$ in the absence of $\mathrm{H}_{2} \mathrm{O}_{2}, 39.1^{\circ} \mathrm{C}$ in $1 \mathrm{nM} \mathrm{H}_{2} \mathrm{O}_{2}$ and $38.8^{\circ} \mathrm{C}$ in $10 \mathrm{nM} \mathrm{H}_{2} \mathrm{O}_{2}$. (F) No increase of [Ca] in neutrophils from $\mathrm{TRPM}^{-1-}$ mice. Traces are from single neutrophils representative of $15-20$ cells total in $n=3$ separate experiments using neutrophils from 3 mice; all traces had closely similar form. Neutrophil calcium imaging performed in flowing solution in absence of chemotactic gradient (see Methods). Calibration for conversion of $\mathrm{F}_{340 / 380}$ ratio to [Ca $]_{i}$ shown in last panel in $\mathrm{G}$ (see Methods).

\section{G, $\mathrm{H}$ : Calcium entry elicited by TRPM2-dependent chemoattractants $\mathrm{H}_{2} \mathrm{O}_{2}, A D P R$ and} fMLP. (G) Increase of [Ca] in response to application of (from left) $\mathrm{H}_{2} \mathrm{O}_{2}(10 \mu M), A D P R$ $(100 \mu M)$ and $\mathrm{fMLP}(1 \mu \mathrm{M})$, in neutrophils from WT mice. In the $\mathrm{H}_{2} \mathrm{O}_{2}$ experiment (first panel) the $[\mathrm{Ca}]_{i}$ rapidly decreased when external calcium was removed (nominal OCa, no EGTA) consistent with Ca entry from the external solution via TRPM2 (Note contracted time scale in this panel). The trace in fMLP shows an example of the method used to convert $F_{340 / 380}$ to $\left[\mathrm{Ca}\right.$, by measuring $\mathrm{F}_{\max }$ with exposure to the Ca ionophore ionomycin $(10 \mu \mathrm{M})$, followed by $\mathrm{F}_{\min }$ in $0 \mathrm{Ca} / 2 \mathrm{mM}$ EGTA. $(\mathrm{H})$ No increase of $[\mathrm{Ca}]_{i}$ in neutrophils from $\mathrm{TRPM}^{-/-}$mice.

Experimental details as in E, F. All traces from single neutrophils but representative of 15-20 traces from $n=3$ separate experiments using 3 mice. 


\section{Figure 4}

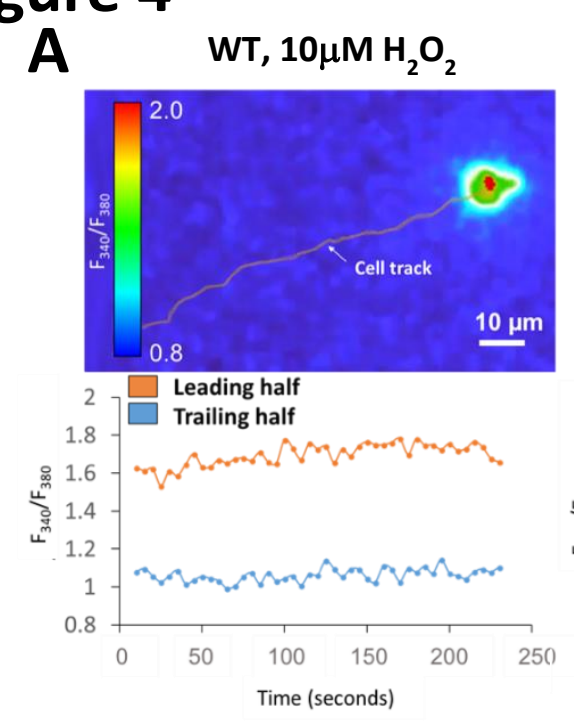

B

D
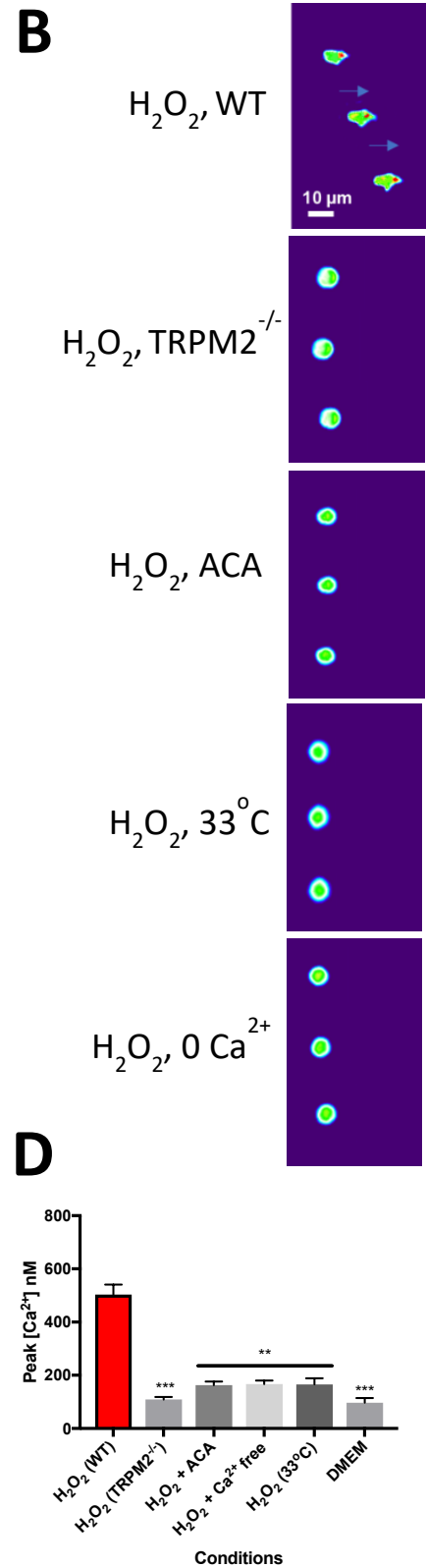
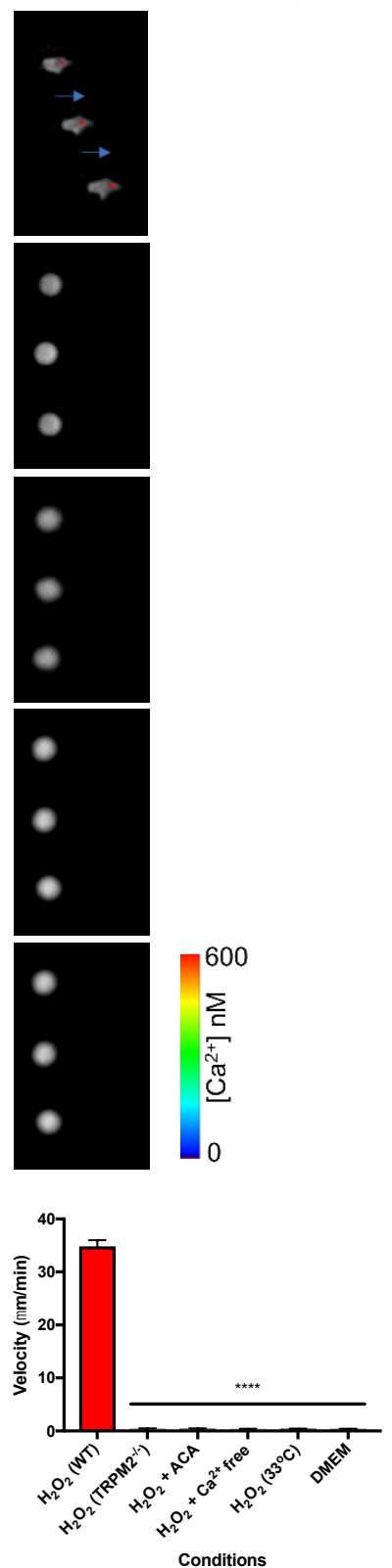

TRPM2 $^{-/-} 10 \mu \mathrm{M} \mathrm{H}_{2} \mathrm{O}_{2}$
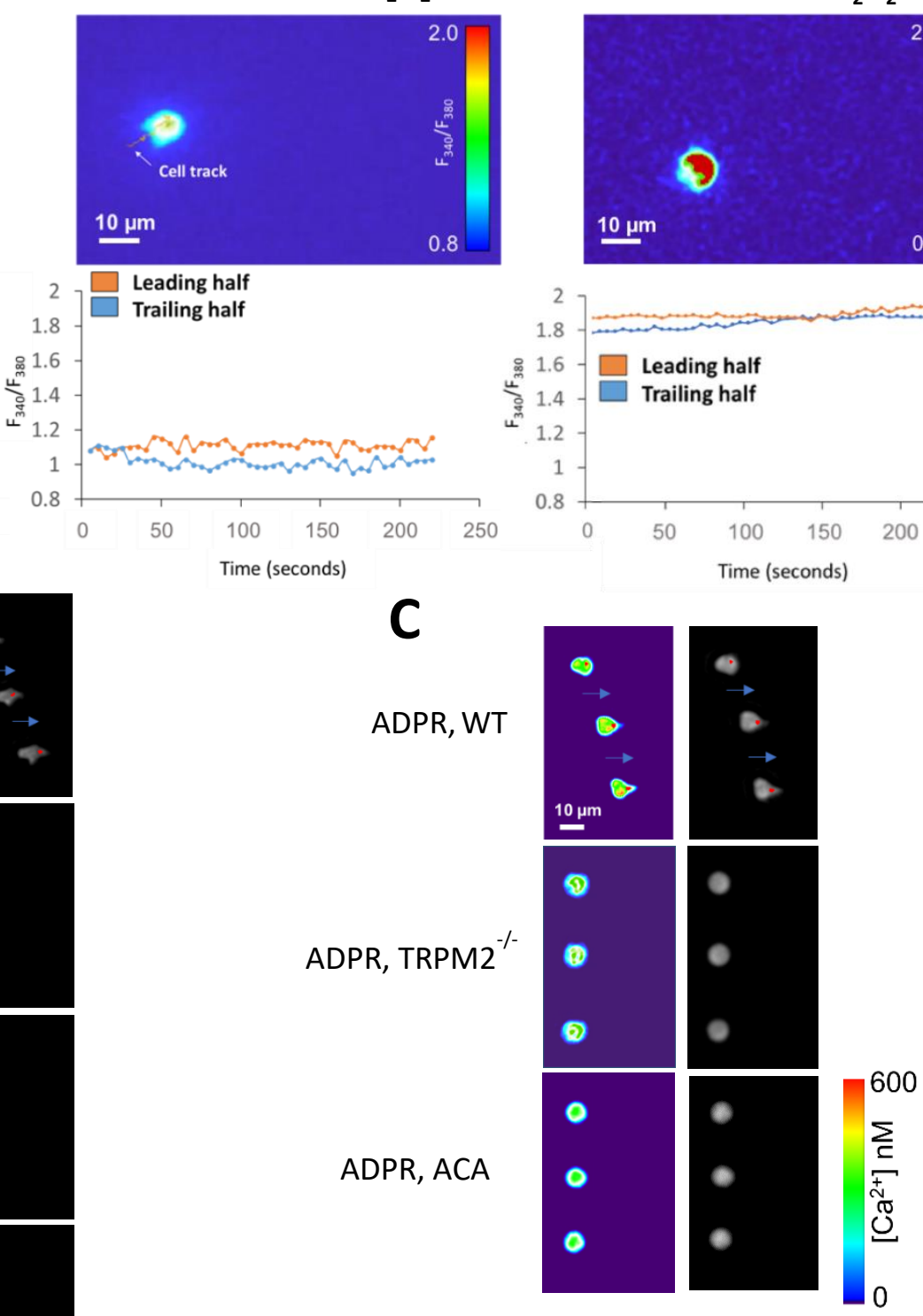

$\mathbf{E}$
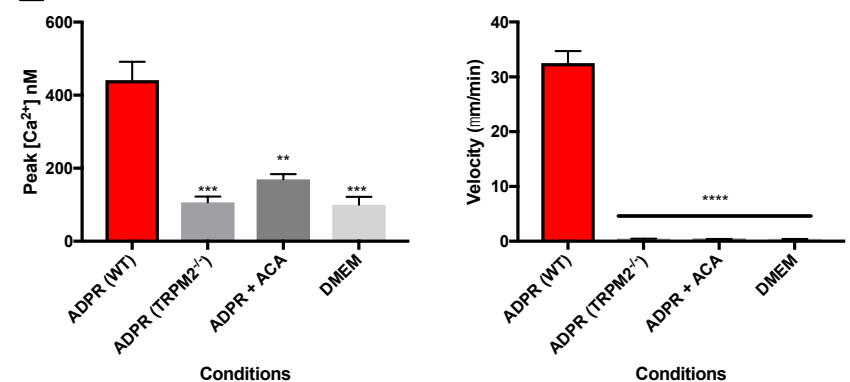
Fig. 4. Neutrophil chemotaxis is accompanied by leading-edge calcium pulses

A. Images show calcium-dependent fluorescence ratio of indicator fura2 with alternating $340 \mathrm{~nm}$ and $380 \mathrm{~nm}$ illumination. Left: Wild-type neutrophils migrating up a gradient of $\mathrm{H}_{2} \mathrm{O}_{2}(10 \mu \mathrm{M}$ over $1 \mathrm{~mm}$, left to right) show elevated intracellular calcium at the leading half of the cell in the direction of the gradient (see lower graph). Centre: When TRPM 2 is deleted, neutrophils show no net migration, and the difference between leading and trailing edge calcium is close to zero. Right: In a higher concentration gradient of $\mathrm{H}_{2} \mathrm{O}_{2}(100 \mu \mathrm{M})$ migration is inhibited and calcium concentration is uniformly high throughout the cell. Images representative of $n=3$ individual experiments. Similar experiments in Supplementary Fig. 4 show effect of ADPR and temperature.

B. Chemotaxis towards is $\mathrm{H}_{2} \mathrm{O}_{2}$ accompanied by leading-edge calcium pulses. Left: colour-coded calcium images (scale shown at bottom). Right: maximal calcium concentration (red) superimposed on brightfield phase-contrast images. Both chemotaxis and calcium pulses are abolished by deletion or pharmacological block of TRPM 2 with ACA $(10 \mu \mathrm{M})$, by withdrawal of extracellular calcium or by lowering the temperature to $33^{\circ} \mathrm{C}$. Fast-moving individual neutrophils selected for imaging. Images acquired at $0.5 \mathrm{~s}$ intervals; time between each image shown is 10 s. Long blue arrows indicate movement of neutrophil by a distance equal to or above the cell diameter in the time interval of $10 \mathrm{~s}$. Gradient of $\mathrm{H}_{2} \mathrm{O}_{2} 10 \mu \mathrm{M}$ over $1 \mathrm{~mm}$, except bottom panel which is $10 \mathrm{nM}$ over $1 \mathrm{~mm}$. Other concentrations as in Fig. 2. Images representative of $\mathrm{n}=3$ individual experiments.

C. Calcium pulses and chemotaxis in a gradient of ADPR $(100 \mu \mathrm{M})$ are abolished by genetic deletion of TRPM 2 and by the TRPM2 blocker ACA $(10 \mu \mathrm{M})$. Other details as in $\mathrm{B}$.

D. Peak calcium (left) and cell velocity (right) for the conditions shown in B. Peak [Ca ${ }^{2+}$ ] averaged over $n=40$ images in each series (sample images shown in B). Velocity calculated as in Fig. 1C. Bars show average of $n=3$ individual cells. One-way ANOVA and Tukey-Kramer post-hoc test compared to first bar. ${ }^{*}, \mathrm{p}<0.05 ;{ }^{* *}, \mathrm{p}<0.01 ; * * *$, $\mathrm{p}<0.001 ; * * * *, \mathrm{p}<0.0001$

E. Similar plots for data shown in C. 


\section{Figure 5}
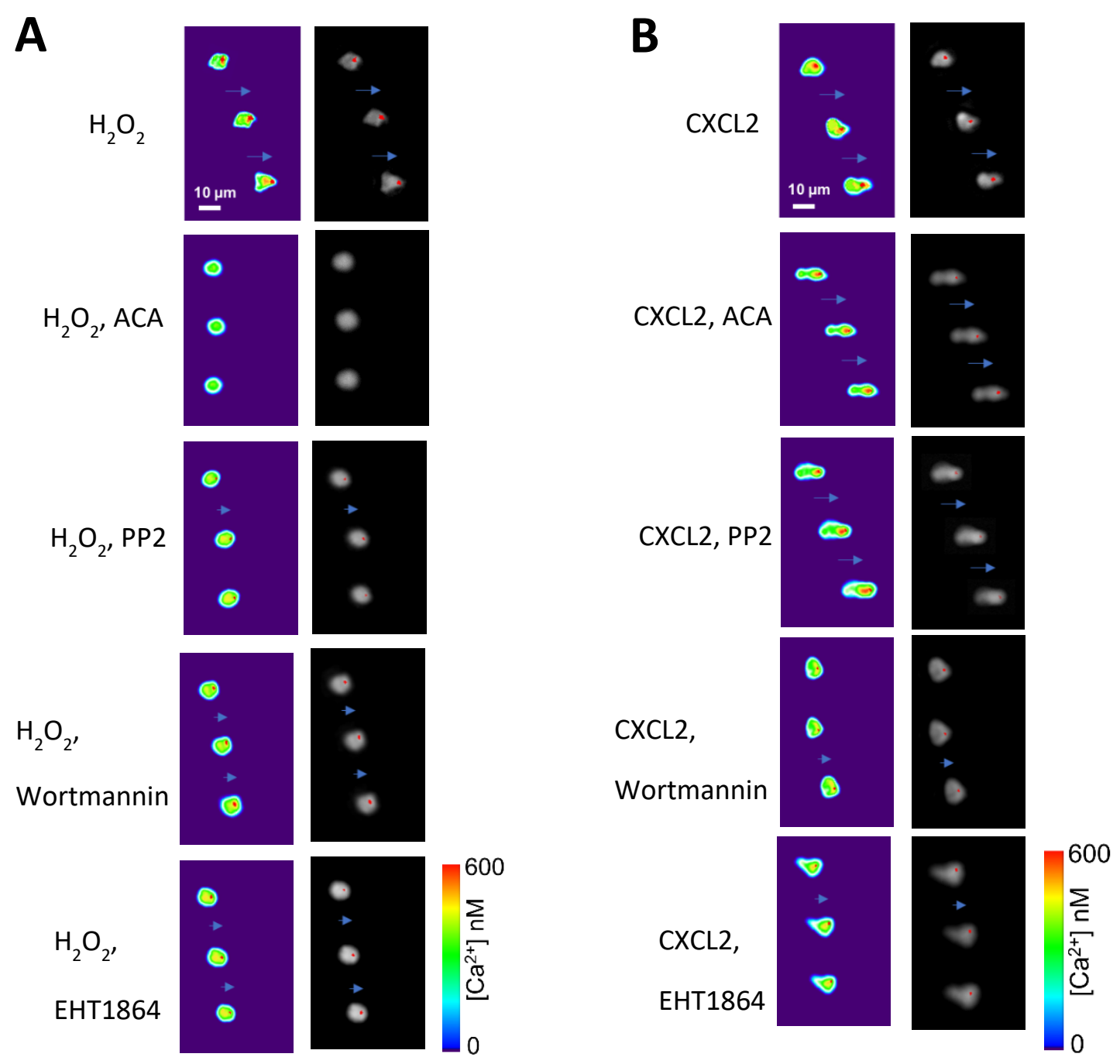

C

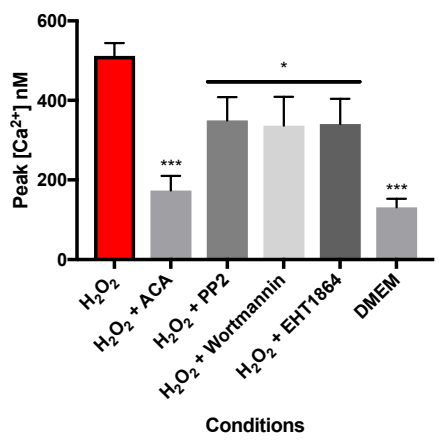

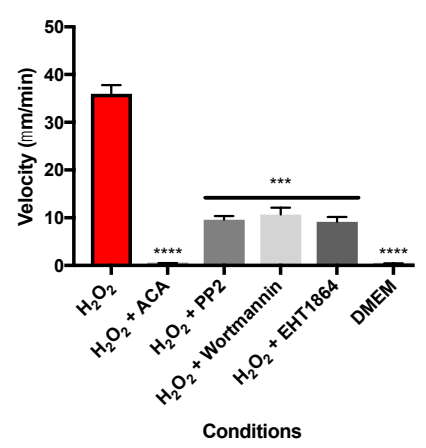

Conditions
D
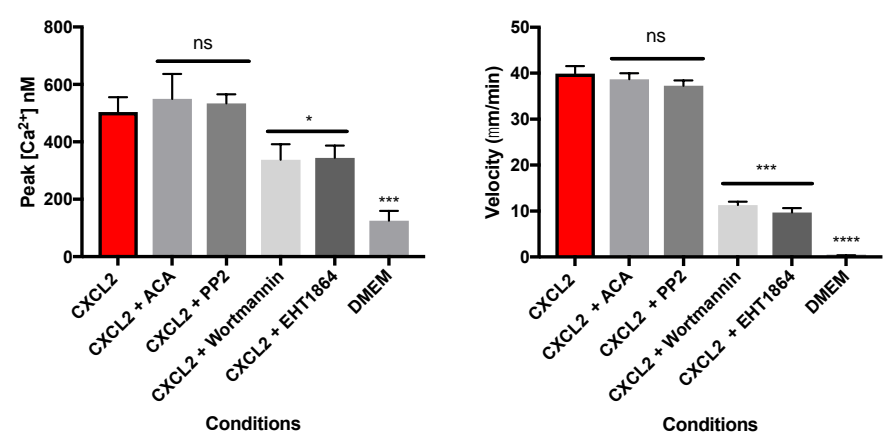


\section{Fig. 5. Effect of pharmacological blockers on neutrophil migration towards $\mathrm{H}_{2} \mathrm{O}_{2}$ and} chemokine CXCL2.

A. Gradient of $\mathrm{H}_{2} \mathrm{O}_{2}(10 \mu \mathrm{M}$ over $1 \mathrm{~mm})$. From top: $\mathrm{H}_{2} \mathrm{O}_{2}$ alone; TRPM2 blocker ACA ( $\mathrm{N}$ (p-amylcinnamoyl)anthranilic acid, $10 \mu \mathrm{M}$ ) completely inhibits both migration and $\mathrm{Ca}$ pulses (reproduced from Fig. 4); migration is slowed and $\mathrm{Ca}^{2+}$ pulses partially inhibited by the Src-family kinase inhibitor PP2 (10 $\mu \mathrm{M})$, PI3kinase inhibitor wortmannin (100 nM) and Rac inhibitor EHT 1864 (50 $\mu \mathrm{M})$. Images shown at 10s intervals in each panel. Long blue arrows - movement of neutrophil a distance equal to or greater than the cell diameter; arrowheads - movement less than cell diameter; no arrow - no significant movement. Other details as in Fig. 4. Images representative of $n=3$ individual experiments.

B. Similar experiment with gradient of $\mathrm{CXCL2}(10 \mathrm{nM})$. Migration and $\mathrm{Ca}^{2+}$ pulses are unaffected by ACA $(10 \mu \mathrm{M})$ and PP2 $(10 \mu \mathrm{M})$, while migration is slowed and $\mathrm{Ca}^{2+}$ pulse amplitude reduced by wortmannin (100 $\mathrm{nM})$ and ETH 1864 (50 $\mu \mathrm{M})$. Images representative of $n=3$ individual experiments.

C. Peak calcium (top) and cell velocity (bottom) for the conditions shown in A. Bars show average of $n=3$ individual cells. Two-way ANOVA and Tukey-Kramer post-hoc test compared to first bar. ${ }^{*}, \mathrm{p}<0.05 ;{ }^{* *}, \mathrm{p}<0.001 ; * * * *, \mathrm{p}<0.0001, \mathrm{~ns}=$ not significant. Other details as in Fig. 4.

D. Similar plots for data shown in B.

Similar experiments for conventional chemoattractants C5a and LPS shown in Supplementary Materials Fig 5. 


\section{Figure 6}

A

1

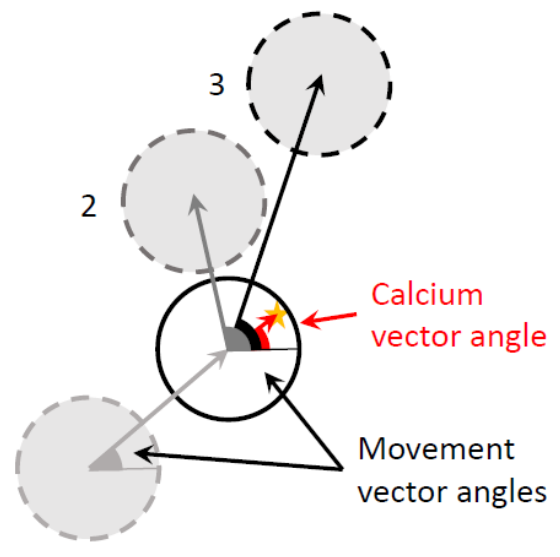

B

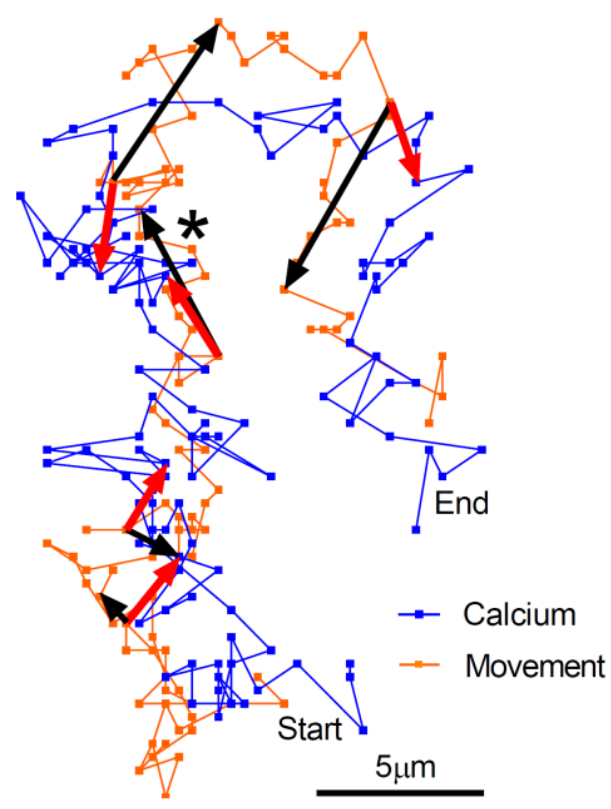

C
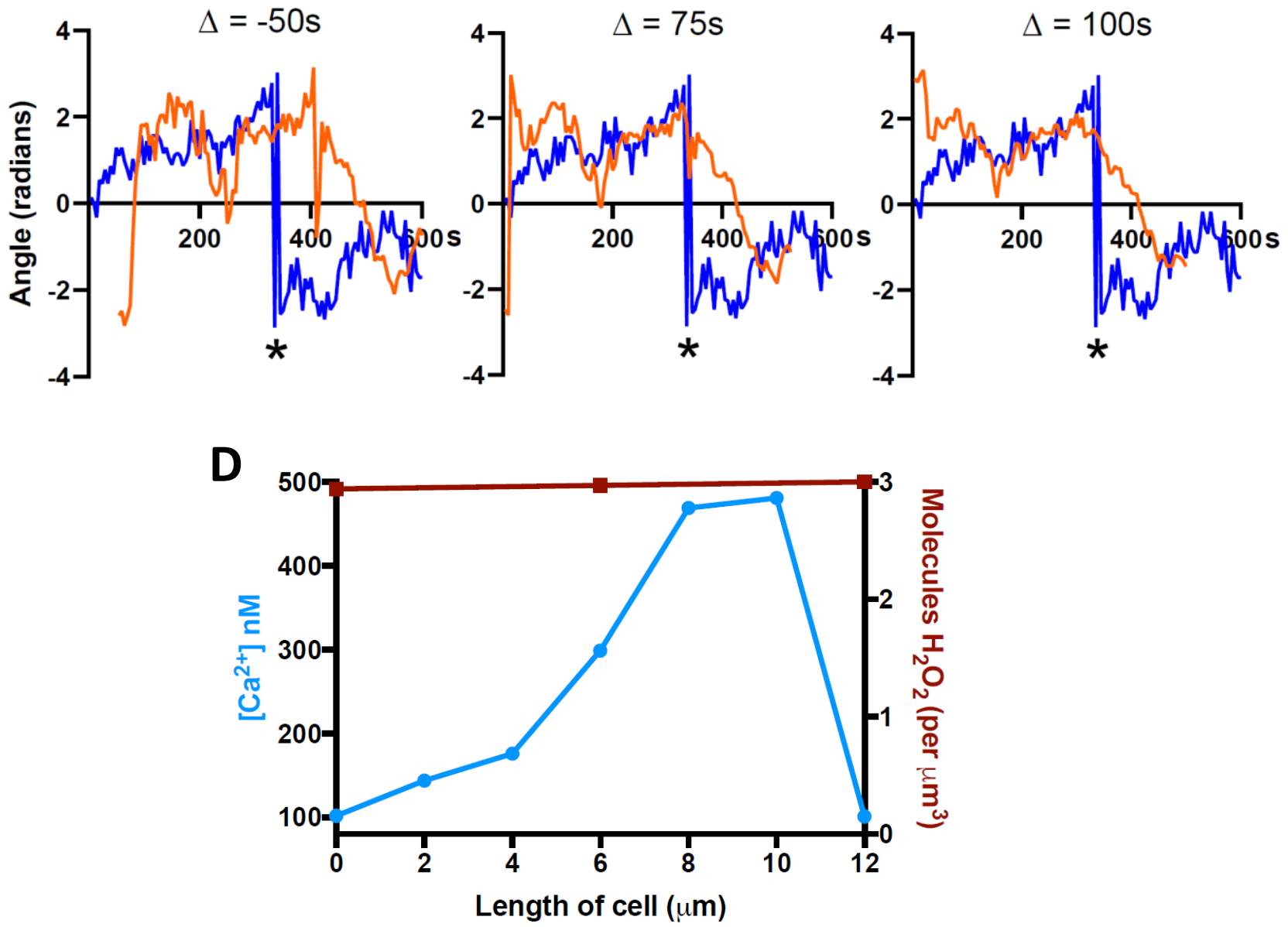


\section{Fig. 6. Calcium pulses direct neutrophil chemotaxis}

A. Method for determining the relation between direction of calcium pulses and direction of neutrophil movement. Red vector ("calcium vector") shows direction in which the calcium pulse is "pointing", by connecting cell geometric centre to simultaneous location of maximal calcium signal, while grey or black vectors show direction of movement of cell geometric centre ("movement vector"), which can be calculated at earlier (1) or later times $(2,3)$.

B. Tracks of geometric cell centre (orange) and position of peak calcium concentration (blue) at 5 s intervals for a neutrophil moving in absence of chemotactic gradient. (See movie in Supplementary Video File 2). Similar image series taken at a 10x shorter intervals did not show any obvious difference in the dynamics of movement of peak calcium concentration (Supplementary Materials Fig. 8). Red vectors (shown at 100 s intervals) give direction of calcium vector (see A). Black vectors show movement vector (see A) connecting the geometric centre at the same time as each calcium vector with the geometric centre 50 s later. At the time indicated by the star the calcium vector shifts abruptly from an average upward orientation to an average downward orientation. There is a clear delay before the movement vector follows.

C. Calcium vector (blue) and movement vector (orange) angles for cell shown in B. A delay of $75 \mathrm{~s}$ best predicts the moment at which the movement vector begins to follow the abrupt change in direction of calcium vector. There is a further delay before the cell movement aligns with the new calcium vector orientation (half-time c. 83s), giving total delay between change of calcium vector and half-alignment of movement vector of 158s.

D. Calcium concentration (blue), determined from fura-2 fluorescence ratio, shown in the in the direction of migration from left to right of a neutrophil located half-way up a gradient of $\mathrm{H}_{2} \mathrm{O}_{2}$ from 0 to $10 \mathrm{nM}$. For comparison, red line shows $\mathrm{H}_{2} \mathrm{O}_{2}$ concentration (in molecules of $\mathrm{H}_{2} \mathrm{O}_{2}$ per $\mu \mathrm{m}^{3}$ ) along the length of the cell. Horizontal axis gives distance from left-hand to right-hand edges of the cell, in the direction both of the $\mathrm{H}_{2} \mathrm{O}_{2}$ gradient and of cell motion. 


\section{Materials and Methods}

\section{Animals}

Black C57BL/6 WT and TRPM2 ${ }^{-/-} \mathrm{K} / \mathrm{O}$ mice (6-8 weeks old) were bred in house from matings of TRPM2 ${ }^{+/-}$heterozygous mice to ensure that the genetic and environmental backgrounds of both WT and TRPM2-/- mice were as far as possible identical. TRPM2-- $\mathrm{K} / \mathrm{O}$ mice were a gift from the Mori laboratory (Kyoto, Japan) ${ }^{43}$ and had been backcrossed onto the WT C57BL/6 strain for nine generations. For experiments in which comparisons with $\mathrm{K} / \mathrm{O}$ were not required, Black C57BL/6 WT mice (6-8 weeks old) were purchased from Charles River Inc. All animal work was conducted under UK Home Office personal and project licences, approved by the Animal Welfare Ethical Review Board (AWERB) of King's College London and carried out in accordance with The Animals (Scientific Procedures) Act 1986 and in compliance with the ARRIVE guidelines.

\section{Chemicals and reagents}

Hydrogen peroxide $\left(\mathrm{H}_{2} \mathrm{O}_{2}, 31642\right)$, adenosine 5'diphosphoribose (ADPR, A0752), Nformylmethionine-leucyl-phenylalanine (fMLP, F3506), thioglycolate (70157), lipopolysaccharide (LPS, LPS25), CXCL2 (SRP4251), complement component 5a (C5a, SRP4895A), N-(p-Amylcinnamoyl)anthranilic acid (ACA, A8486), PP2 (P0042), interleukin-8 (IL-8, CXCL8 SRP3098) were purchased from Sigma-Aldrich (Sigma-Aldrich Company Ltd., Dorset, UK). Wortmannin (W1628) was purchased from Yorlab (York, UK) and EHT1864 (3872/10) was purchased from Bio-Teche (Minnesota, US). Pluronic F-127 (P3000MP) and Fura-2AM (F1221) were purchased from Thermo Fisher Scientific (Thermo Fisher Scientific Life Technologies, Waltham, Massachusetts, U.S). The RAL DIFF-QUIK kit (a modified version of the May-Grünwald-Giemsa stain)) (RAL555) was purchased from RAL Diagnostics, (RAL Diagnostics, Martillac, France).

\section{In vivo model: measurement of $\mathrm{H}_{2} \mathrm{O}_{2}$-induced peritoneal cell chemotaxis}

An in vivo model was developed in which $\mathrm{WT}$ and TRPM2 $\mathrm{K} / \mathrm{O}$ mice were subjected to intraperitoneal (IP) injection (10 $\mu \mathrm{l} / \mathrm{g})$ of: $0,0.001,0.01,0.1,1,10$ or $100 \mu \mathrm{M} \mathrm{H}_{2} \mathrm{O}_{2}$ or $1 \mu \mathrm{M}$ fMLP in $\mathrm{H}_{2} \mathrm{O}$. After a variable time mice were euthanised, skin covering the peritoneum was removed, $5 \mathrm{ml}$ PBS injected into the peritoneal cavity and the cavity massaged gently for $60 \mathrm{~s}$ to dislodge cells. The peritoneal fluid was extracted and centrifuged for 10 mins at 200 RCF. The supernatant was discarded and the cells suspended in DMEM (Thermo Fisher Scientific Cat. No. $41966-029)+10 \%$ FBS. The total number of cells recovered was counted, using a 
Neubauer chamber, as a semi-quantitative measure of cell chemotaxis. Cell numbers were corrected for the amount of fluid recovered as a fraction of $5 \mathrm{ml}$.

\section{Isolation of mouse peritoneal neutrophils}

Mice were injected IP with $3 \%$ thioglycolate solution $(10 \mu \mathrm{l} / \mathrm{g})$ and, after $4 \mathrm{~h}$, euthanised by cervical dislocation. The peritoneal-covering skin was removed, $5 \mathrm{ml}$ PBS injected into the peritoneal cavity and massaged gently for $60 \mathrm{~s}$ to dislodge cells. The peritoneal fluid was extracted and centrifuged for 10 mins at 200 RCF. The supernatant was discarded and cells suspended in DMEM + 10\% FBS. This method generated cell suspensions containing >90\% of neutrophils, identified through a fast-acting modified version of the May-Grünwald-Giemsa staining ${ }^{51}$ and subsequent cell type identification (see Supplementary Materials Figure 9).

\section{Cell identification in peritoneal extract}

Cell suspension isolated from peritonea of WT mice as above. Suspensions spun down onto glass slides using a Cytospin at 400 RPM for 5 mins and left to air-dry overnight. A modified version of the May-Grünwald-Giemsa staining was used to identify cell types (RAL DIFF-QUIK kit, RAL diagnostics). Slides were suspended in RAL Diff-Quick fixative solution (methanol based solution to stabilize cellular components) for 1 minute, in RAL Diff-Quik solution I (Xanthene solution; a buffered solution of Eosin Y) for 1 minute and in RAL Diff-Quik solution II (a buffered solution of thiazine dyes, consisting of methylene blue and Azure A) for 1 minute. Nuclei were meta-chromatically stained red/purple and cytoplasm pink/yellow (See Supplementary Materials Fig. 9).

\section{Isolation of human blood neutrophils}

Blood samples were collected from healthy volunteers by Dr Lucy Norling at Queen Mary College, University of London, with written consent. Human cells were prepared according to a protocol approved by the East London \& The City Local Research Ethics Committee (no. 06/Q605/40; P/00/029 ELCHA, London, United Kingdom) and kindly donated for use in our experiments. Blood was collected into $3.2 \%$ sodium citrate and diluted 1:1 in RPMI 1640 before separation through a double-density gradient as described ${ }^{52}$.

\section{In vitro Boyden chamber neutrophil migration assay}

QCM Boyden chamber chemotaxis neutrophil migration assay kits were purchased from Merck Millipore (ECM505, Massachusetts, USA). Neutrophil chemotaxis cell migration assays were conducted according to manufacturer's instructions. In brief, neutrophils, isolated and prepared as above were seeded at $2 \times 10^{5}$ cells per insert and each insert placed in a chamber 
containing either DMEM medium alone, $0.001 \mu \mathrm{M}, 0.01 \mu \mathrm{M}, 0.1 \mu \mathrm{M}, 1 \mu \mathrm{M}, 10 \mu \mathrm{M}, 100 \mu \mathrm{M}$ $\mathrm{H}_{2} \mathrm{O}_{2}$ or $1 \mu \mathrm{M}$ fMLP. Inserts and chambers were incubated at $37^{\circ} \mathrm{C}$ in $95 \%$ air $/ 5 \% \mathrm{CO}_{2}$ for 4 hrs to allow cells to migrate through neutrophil-specific $3 \mu \mathrm{m}$ pores. Non-migrated cells were removed from the inserts and the inserts placed in cell-detachment solution for 30 mins at $37^{\circ} \mathrm{C}$ in $95 \%$ air $/ 5 \% \mathrm{CO}_{2} .112 \mu \mathrm{l}$ of this solution and of the lower chamber were added to the same wells of black-walled 96 well plates. Cells were lysed in the wells and incubated with CyQUANT GR dye, which emits increasing fluorescence proportional to the levels of bound nucleic acid released from the lysed cells. Following a 15 min incubation at room temperature, fluorescence intensity was analysed on a FLUOstar Omega microplate reader (BMG LABTECH, Buckinghamshire, UK) at 480/520 nm.

\section{Neutrophil chemotaxis assays}

Ibidi $\mu$-slide chemotaxis assay chambers, precoated with collagen IV along the central migration strip, were purchased from Thistle Scientific Ltd (Uddingston, Glasgow, UK). Neutrophils, isolated as above from peritonea of WT or TRPM2 K/O mice or from human blood, were re-suspended within 30min of collection in DMEM $+10 \%$ FBS at a concentration of $5 \times 10^{5}$ cells per $\mathrm{ml}$ and $6 \mu \mathrm{l}$ was seeded along the central migration strip of an lbidi $\mu$-slide chamber as per the manufacturer's instructions. Slides were incubated for $1 \mathrm{hr}$ at $37^{\circ} \mathrm{C}$ in humidified $95 \%$ air $/ 5 \% \mathrm{CO}_{2}$, to allow neutrophil adherence to the central migration strip. DMEM (without added FBS) with and without added chemoattractant was then added to the wells on opposite sides of the central migration strip. DMEM was from Thermo Fisher Scientific Cat. No. 41966-029, or for experiments in which the effects of calcium removal were studied, 0Ca DMEM was from Thermo Fisher Scientific Cat. No. 21068-028. For experiments in which effects of inhibitors were to be tested, equal concentrations were added to both DMEM + chemoattractant and DMEM wells. Slides were pre-incubated at $37^{\circ} \mathrm{C}$ in $95 \%$ air $/ 5 \% \mathrm{CO}_{2}$ for 20 mins to allow the generation of a gradient of chemoattractant across the $1 \mathrm{~mm}$ wide $\times 70 \mu \mathrm{m}$ deep central cell migration strip. Live-cell time-lapse microscopy was then conducted using a 10x lens and dark-field illumination on a Nikon Eclipse Ti-E inverted microscope equipped with the Nikon Perfect Focus System (PFS). The images shown are centered on the middle of the $1 \mathrm{~mm}$ wide cell migration strip and span the majority of its width. The microscope was housed in a temperature-controlled Perspex box (Solent Scientific) at $37^{\circ} \mathrm{C}$, or other temperatures as desired, with slides housed in a stage-mounted block in humidified $95 \%$ air $/ 5 \% \mathrm{CO}_{2}$. A maximum of 12 individual chambers (4 individual slides, 3 chambers per slide) could be imaged per experiment by using a motorized stage. Stage movement, lens focus and image acquisition were controlled by Nikon NIS Elements software. Experiments were conducted over $2 \mathrm{~h}$, with images of each assay compartment taken every 2 min. The ImageJ Fiji TrackMate plug-in was employed to track individual neutrophils. A chemotaxis and migration 
plug-in, provided by ibidi, was used to calculate speed and forward migration index (FMI) data from the neutrophil tracks.

\section{Calcium imaging of neutrophils}

Neutrophils isolated as above were re-suspended in DMEM $+10 \%$ FBS at a concentration of $5 \times 10^{5}$ per $\mathrm{ml}$.

For experiments in which intracellular calcium was to be recorded while extracellular solutions were changed, neutrophils were plated onto a collagen-coated $13 \mathrm{~mm}$ round glass coverslip and incubated at $37^{\circ} \mathrm{C}$ in $95 \%$ air $/ 5 \% \mathrm{CO} 2$ for $1 \mathrm{~h}$ to allow neutrophils to adhere. Fura2-AM (5 UM in DMEM) was then added to the cells on the coverslip for 30 mins at $37^{\circ} \mathrm{C}$ in $95 \%$ air $/ 5 \%$ $\mathrm{CO}_{2}$. Fluorescence was measured during alternating illumination at $340 \mathrm{~nm}$ and $380 \mathrm{~nm}$ (OptoScan; Cairn Research Inc, Kent, UK) every 2 seconds using a Nikon Eclipse Ti inverted microscope with a 40x lens and iXon 897 EM-CCD camera controlled by WinFluor 3.2 software. $F_{340 / 380}$ ratios were obtained using FIJI (ImageJ) and converted to calcium concentrations using the equation given by Grynkiewicz et al with values $R_{\max }=2.501, R_{\min }=$ 0.103 , both determined experimentally, see Fig. 3G. Full details in Vilar et $\mathrm{al}^{53}$.

For experiments when calcium signals during chemotaxis up a gradient of chemoattractant were to be recorded, $1 \mu \mathrm{l}$ of Fura-2 AM solution (50 $\mu$ g Fura-2 AM + $10 \mu$ l pluronic F-127 + 10 $\mu \mathrm{l}$ DMSO) was added to $500 \mu \mathrm{l}$ of neutrophil suspension and incubated for $1 \mathrm{hr}$ at $37^{\circ} \mathrm{C}$ in $95 \%$ air $/ 5 \% \mathrm{CO}_{2}$. Fura-2 loaded cells in suspension were seeded into ibidi chambers as previously and imaged in a Nikon Ti-E microscope with a 40x phase contrast lens. Fastmoving neutrophils located in the middle of the central cell migration strip were selected, with typically only one cell imaged per field. Calcium ratio images were obtained with alternating 340nm and 380nm epi-illumination supplied by stable LED light sources (Fura-LED, Cairn Research), typically at $5 \mathrm{~s}$ intervals. In some experiments acquisition of each pair of epifluorescence images was followed by a transmitted white-light phase-contrast image. All images were filtered by a broad-band $510 \mathrm{~nm}$ filter and captured with a Photometrics Prime 95B sCMOS camera. Stage movement, focus and image acquisition were controlled by Nikon NIS Elements software. The ImageJ Fiji RatioPlus plug-in was used to generate $F_{340 / 380}$ ratio images and a rainbow look-up table (LUT) was applied to the ratio images to indicate the level of calcium. Values of the ratio $F_{340 / 380}$ were converted to intracellular free calcium concentration using the equation given by Grynkiewicz et al. ${ }^{54}$. To determine the values of fluorescence ratios at maximal $\left(R_{\max }\right)$ and zero $\left(R_{\min }\right)$ calcium levels, neutrophils were imaged in the presence of ionomycin $(10 \mu \mathrm{M})$ either in DMEM or in OCa DMEM with added 2mM EGTA, giving mean values $R_{\max }=3.132$ and $R_{\min }=0.803$ (note that the differences between these values and those above arises because chemotaxis experiments were performed on different 
apparatus). To indicate the location of the maximum calcium level on a phase-contrast image, a 3-colour LUT was applied to an $F_{340 / 380}$ ratio image and the red channel (highest $F_{340 / 380}$ ) was selected and superimposed on the phase-contrast image. The coordinates of the region of highest calcium within the cell were identified in $\mathrm{F}_{340 / 380}$ images using the Fiji maximum intensity identifying tool. The coordinates for the geometric centre of the neutrophil were identified using the cell edge and centre localising tool. In some images (for example, Fig. 4A) mean values of $F_{340 / 380}$ in leading and trailing halves was calculated by identifying the cell outline using the cell edge localising tool and dividing the cell by hand into leading and trailing halves in the direction of the imposed chemotactic gradient. 
Acknowledgements. Supported by a grant from the Wellcome Trust to PMcN and by a KCL Biomedical Research Centre PhD studentship to HM. SL acknowledges the Department of Health Research (DHR), Ministry of Health \& Family Welfare, Government of India for awarding a Long-Term Fellowship at KCL, UK. We thank Dr Larissa Pinto for assistance with histochemistry and Dr Lucy Norling and Professor Mauro Perretti for supplying human blood neutrophils. 


\section{References}

1 Kolaczkowska, E. \& Kubes, P. Neutrophil recruitment and function in health and inflammation. Nat Rev Immunol 13, 159-175, doi:10.1038/nri3399 (2013).

2 Klyubin, I. V., Kirpichnikova, K. M. \& Gamaley, I. A. Hydrogen peroxide-induced chemotaxis of mouse peritoneal neutrophils. European journal of cell biology 70, 347-351 (1996). Niethammer, P., Grabher, C., Look, A. T. \& Mitchison, T. J. A tissue-scale gradient of hydrogen peroxide mediates rapid wound detection in zebrafish. Nature 459, 996-999, doi:10.1038/nature08119 (2009). Niethammer, P. Wound redox gradients revisited. Semin Cell Dev Biol 80, 13-16, doi:10.1016/j.semcdb.2017.07.038 (2018). Jelcic, M., Enyedi, B., Xavier, J. B. \& Niethammer, P. Image-Based Measurement of H2O2 Reaction-Diffusion in Wounded Zebrafish Larvae. Biophys J 112, 2011-2018, doi:10.1016/j.bpj.2017.03.021 (2017). Niethammer, P. The early wound signals. Curr Opin Genet Dev 40, 17-22, doi:10.1016/j.gde.2016.05.001 (2016). Enyedi, B. \& Niethammer, P. H2O2: a chemoattractant? Methods Enzymol 528, 237-255, doi:10.1016/B978-0-12-405881-1.00014-8 (2013).

8 Razzell, W., Evans, I. R., Martin, P. \& Wood, W. Calcium flashes orchestrate the wound inflammatory response through DUOX activation and hydrogen peroxide release. Current biology : CB 23, 424-429, doi:10.1016/j.cub.2013.01.058 (2013).

9 Yoo, S. K., Starnes, T. W., Deng, Q. \& Huttenlocher, A. Lyn is a redox sensor that mediates leukocyte wound attraction in vivo. Nature 480, 109-112, doi:10.1038/nature10632 (2011). Moreira, S., Stramer, B., Evans, I., Wood, W. \& Martin, P. Prioritization of competing damage and developmental signals by migrating macrophages in the Drosophila embryo. Current biology : CB 20, 464-470, doi:10.1016/j.cub.2010.01.047 (2010).

11 Evans, I. R., Rodrigues, F. S., Armitage, E. L. \& Wood, W. Draper/CED-1 mediates an ancient damage response to control inflammatory blood cell migration in vivo. Current biology : $C B$ 25, 1606-1612, doi:10.1016/j.cub.2015.04.037 (2015).

12 Takahashi, N., Kozai, D., Kobayashi, R., Ebert, M. \& Mori, Y. Roles of TRPM2 in oxidative stress. Cell Calcium 50, 279-287, doi:S0143-4160(11)00076-5 [pii];10.1016/j.ceca.2011.04.006 [doi] (2011).

13 Knowles, H. et al. Transient Receptor Potential Melastatin 2 (TRPM2) ion channel is required for innate immunity against Listeria monocytogenes. Proc Natl Acad Sci U S A 108, 1157811583, doi:10.1073/pnas.1010678108 (2011).

14 Mei, Z. Z., Xia, R., Beech, D. J. \& Jiang, L. H. Intracellular coiled-coil domain engaged in subunit interaction and assembly of melastatin-related transient receptor potential channel 2. J Biol Chem 281, 38748-38756, doi:10.1074/jbc.M607591200 (2006). Shen, B. W., Perraud, A. L., Scharenberg, A. \& Stoddard, B. L. The crystal structure and mutational analysis of human NUDT9. Journal of molecular biology 332, 385-398 (2003). Perraud, A. L. et al. ADP-ribose gating of the calcium-permeable LTRPC2 channel revealed by Nudix motif homology. Nature 411, 595-599, doi:10.1038/35079100 (2001).

17 Montell, C., Birnbaumer, L. \& Flockerzi, V. The TRP channels, a remarkably functional family. Cell 108, 595-598 (2002).

18 Iordanov, I., Mihalyi, C., Toth, B. \& Csanady, L. The proposed channel-enzyme transient receptor potential melastatin 2 does not possess ADP ribose hydrolase activity. Elife $\mathbf{5}$, doi:10.7554/eLife.17600 (2016).

19 Toth, B., lordanov, I. \& Csanady, L. Putative chanzyme activity of TRPM2 cation channel is unrelated to pore gating. Proc Natl Acad Sci U S A 111, 16949-16954, doi:10.1073/pnas.1412449111 (2014).

20 Togashi, K. et al. TRPM2 activation by cyclic ADP-ribose at body temperature is involved in insulin secretion. EMBO J. 25, 1804-1815 (2006). 
21 Sumoza-Toledo, A. et al. Dendritic cell maturation and chemotaxis is regulated by TRPM2mediated lysosomal Ca2+ release. FASEB J. 25, 3529-3542, doi:fj.10-178483 [pii];10.1096/fj.10-178483 [doi] (2011).

22 Partida-Sanchez, S. et al. Chemotaxis of mouse bone marrow neutrophils and dendritic cells is controlled by adp-ribose, the major product generated by the CD38 enzyme reaction. $J$ Immunol 179, 7827-7839, doi:10.4049/jimmunol.179.11.7827 (2007).

23 Kraft, R., Grimm, C., Frenzel, H. \& Harteneck, C. Inhibition of TRPM2 cation channels by N-(pamylcinnamoyl)anthranilic acid. Br J Pharmacol 148, 264-273, doi:10.1038/sj.bjp.0706739 (2006).

24 Tan, C. H. \& McNaughton, P. A. The TRPM2 ion channel is required for sensitivity to warmth. Nature 536, 460-463, doi:10.1038/nature19074 (2016).

25 Tan, C. H. \& McNaughton, P. A. TRPM2 and warmth sensation. Pflugers Archiv : European journal of physiology 470, 787-798, doi:10.1007/s00424-018-2139-7 (2018). Kashio, M. \& Tominaga, M. The TRPM2 channel: A thermo-sensitive metabolic sensor. Channels (Austin) 11, 426-433, doi:10.1080/19336950.2017.1344801 (2017).

27 Ramsey, I. S., Delling, M. \& Clapham, D. E. An introduction to trp channels. Annu.Rev.Physiol 68, 619-647 (2006).

28 Clapham, D. E. SnapShot: mammalian TRP channels. Cell 129, 220 (2007).

29 Bienert, G. P. \& Chaumont, F. Aquaporin-facilitated transmembrane diffusion of hydrogen peroxide. Biochim Biophys Acta 1840, 1596-1604, doi:10.1016/j.bbagen.2013.09.017 (2014). Togashi, K., Inada, H. \& Tominaga, M. Inhibition of the transient receptor potential cation channel TRPM2 by 2-aminoethoxydiphenyl borate (2-APB). Br.J.Pharmacol. 153, 1324-1330, doi:0707675 [pii];10.1038/sj.bjp.0707675 [doi] (2008).

31 Deng, Q., Yoo, S. K., Cavnar, P. J., Green, J. M. \& Huttenlocher, A. Dual roles for Rac2 in neutrophil motility and active retention in zebrafish hematopoietic tissue. Dev Cell 21, 735745, doi:10.1016/j.devcel.2011.07.013 (2011).

32 Houslay, D. M. et al. Coincident signals from GPCRs and receptor tyrosine kinases are uniquely transduced by PI3Kbeta in myeloid cells. Science signaling 9 , ra82, doi:10.1126/scisignal.aae0453 (2016).

33 Yoo, S. K. et al. Differential regulation of protrusion and polarity by PI3K during neutrophil motility in live zebrafish. Dev Cell 18, 226-236, doi:10.1016/j.devcel.2009.11.015 (2010). Graziano, B. R. et al. A module for Rac temporal signal integration revealed with optogenetics. J Cell Biol 216, 2515-2531, doi:10.1083/jcb.201604113 (2017).

35 Zhang, X., Huang, J. \& McNaughton, P. A. NGF rapidly increases membrane expression of TRPV1 heat-gated ion channels. EMBO J 24, 4211-4223 (2005).

36 Brundage, R. A., Fogarty, K. E., Tuft, R. A. \& Fay, F. S. Calcium gradients underlying polarization and chemotaxis of eosinophils. Science 254, 703-706, doi:10.1126/science.1948048 (1991).

37 Marks, P. W., Hendey, B. \& Maxfield, F. R. Attachment to fibronectin or vitronectin makes human neutrophil migration sensitive to alterations in cytosolic free calcium concentration. $J$ Cell Biol 112, 149-158 (1991).

38 Laffafian, I. \& Hallett, M. B. Does cytosolic free Ca2+ signal neutrophil chemotaxis in response to formylated chemotactic peptide? J Cell Sci 108 ( Pt 10), 3199-3205 (1995).

39 Ball, J. A., Vlisidou, I., Blunt, M. D., Wood, W. \& Ward, S. G. Hydrogen Peroxide Triggers a Dual Signaling Axis To Selectively Suppress Activated Human T Lymphocyte Migration. J Immunol 198, 3679-3689, doi:10.4049/jimmunol.1600868 (2017).

40 Wang, G. et al. Oxidant Sensing by TRPM2 Inhibits Neutrophil Migration and Mitigates Inflammation. Dev Cell 38, 453-462, doi:10.1016/j.devcel.2016.07.014 (2016).

41 Berridge, M. J. Inositol trisphosphate and calcium signalling mechanisms. Biochim Biophys Acta 1793, 933-940, doi:10.1016/j.bbamcr.2008.10.005 (2009). 
42 Berridge, M. J. The Inositol Trisphosphate/Calcium Signaling Pathway in Health and Disease. Physiol Rev 96, 1261-1296, doi:10.1152/physrev.00006.2016 (2016).

43 Yamamoto, S. et al. TRPM2-mediated Ca2+influx induces chemokine production in monocytes that aggravates inflammatory neutrophil infiltration. Nat.Med. 14, 738-747, doi:nm1758 [pii];10.1038/nm1758 [doi] (2008).

44 Hiroi, T. et al. Neutrophil TRPM2 channels are implicated in the exacerbation of myocardial ischaemia/reperfusion injury. Cardiovasc. Res. 97, 271-281, doi:cvs332 [pii];10.1093/cvr/cvs332 [doi] (2013).

45 Rios, E. Calcium-induced release of calcium in muscle: 50 years of work and the emerging consensus. The Journal of general physiology 150, 521-537, doi:10.1085/jgp.201711959 (2018).

46 Francis, E. A. \& Heinrich, V. Extension of chemotactic pseudopods by nonadherent human neutrophils does not require or cause calcium bursts. Science signaling 11, doi:10.1126/scisignal.aal4289 (2018).

47 Tsai, F. C. \& Meyer, T. Ca2+ pulses control local cycles of lamellipodia retraction and adhesion along the front of migrating cells. Current biology : CB 22, 837-842, doi:10.1016/j.cub.2012.03.037 (2012).

48 Falke, J. J. \& Ziemba, B. P. Interplay between phosphoinositide lipids and calcium signals at the leading edge of chemotaxing ameboid cells. Chem Phys Lipids 182, 73-79, doi:10.1016/j.chemphyslip.2014.01.002 (2014).

49 Beerman, R. W. et al. Direct In Vivo Manipulation and Imaging of Calcium Transients in Neutrophils Identify a Critical Role for Leading-Edge Calcium Flux. Cell Rep 13, 2107-2117, doi:10.1016/j.celrep.2015.11.010 (2015).

50 Matty, M. A., Beerman, R. W. \& Tobin, D. M. Drug-Inducible, Cell-Specific Manipulation of Intracellular Calcium in Zebrafish Through Mammalian TRPV1 Expression. Zebrafish 13, $374-$ 375, doi:10.1089/zeb.2016.29004.mat (2016).

51 Barcia, J. J. The Giemsa stain: its history and applications. Int J Surg Pathol 15, 292-296, doi:10.1177/1066896907302239 (2007).

52 Perretti, M. et al. Mobilizing lipocortin 1 in adherent human leukocytes downregulates their transmigration. Nat Med 2, 1259-1262 (1996).

53 Vilar, B., Tan, C. H. \& McNaughton, P. A. Heat detection by the TRPM2 ion channel. Nature 584, E5-e12, doi:10.1038/s41586-020-2510-7 (2020).

54 Grynkiewicz, G., Poenie, M. \& Tsien, R. Y. A new generation of $\mathrm{Ca2+}$ indicators with greatly improved fluorescence properties. J Biol Chem 260, 3440-3450 (1985). 